\title{
Anthomyzidae (Diptera) of Taiwan: new species but no new records
}

\author{
Jindřich ROHÁČEK \\ Department of Entomology, Silesian Museum, Nádražní okruh 31, CZ-746 01 Opava, Czech Republic; e-mail: rohacek@szm.cz
}

\author{
Accepted: \\ $24^{\text {th }}$ March 2020 \\ Published online: \\ $18^{\text {th }}$ April 2020
}

\begin{abstract}
Species of the family Anthomyzidae (Diptera: Acalyptrata) occurring in Taiwan are reviewed. Eleven species have been recognized, 8 of them new to science. However, because of limited and poorly preserved material, only three species of the genus Anthomyza Fallén, 1810, viz. A. robusta sp. nov. (Chiayi and Nantou Counties, both sexes), A. caesarea sp. nov. (Taichung City area, both sexes) and A. elongata sp. nov. (Chiayi County, female only), are described. The remaining 5 undescribed species, viz. Amygdalops sp. nov. near cuspidatus (Taichung City area), Amygdalops sp. nov. near curtistylus (Nantou and Kinmen Counties), Anthomyza sp. nov. near elongata (Yilan County), Anthomyza sp. nov. (1) near flavosterna (Chiayi County) and Anthomyza sp. nov. (2) near flavosterna (Nantou County), are diagnosed but remain unnamed. A new species group of Anthomyza, viz. the A. flavosterna group, is established and diagnosed, to include the East Palearctic A. flavosterna Sueyoshi \& Roháček, 2003, A. caesarea sp. nov., A. elongata sp. nov. and 3 additional unnamed species from Taiwan, while the remaining $A$. robusta sp nov. belongs to the A. bellatrix group. All six Taiwanese Anthomyza species seem to be associated with montane habitats and could be endemic. It is estimated that up to 20 species of Anthomyzidae could occur in Taiwan. The longitudinal dark pattern of the wing, found in A. caesarea sp. nov., is recorded for the first time in the genus Anthomyza which is the fourth lineage of Anthomyzidae in which this type of pattern has independently evolved. Preliminary keys to Taiwanese species of the genera Amygdalops Lamb, 1914 and Anthomyza are presented.
\end{abstract}

Key words. Diptera, Anthomyzidae, Amygdalops, Anthomyza, biodiversity, biology, distribution, keys, new species, relationships, taxonomy, unnamed species, wing pattern, Taiwan

Zoobank: http://zoobank.org/urn:lsid:zoobank.org:pub:6D0FA077-A0FC-4C46-87F5-3267C5BDDA89

(C) 2020 The Authors. This work is licensed under the Creative Commons Attribution-NonCommercial-NoDerivs 3.0 Licence.

\section{Introduction}

Taiwan has long been a focus of dipterological research. This has also been true for Acalyptrate flies (e.g. DeLFINADo 1971, Lin et al. 1977, SHIAO \& WU 1996, Lin \& CHEN 1999, PAPP 2005, SHIAo 2019) but not for all their families. There is only a single paper recording Anthomyzidae from this country, that being the revision of the Oriental species of Amygdalops Lamb, 1914 in which four species of this genus were reported (ROHÁČEK 2008). This number is only a fragment of the real diversity of Anthomyzidae in Taiwan because this large island is situated in an area of the Oriental Region where a strong influence of the East Palaearctic fauna from neighbouring continental countries (China, Korea) is obvious, particularly in high-montane territories. Considering this influence and also the high probability of endemism, the Taiwanese fauna of Anthomyzidae could be relatively rich although not likely reaching a number (50-60 species) estimated recently for China (ROHÁČEK 2018).

The Anthomyzidae is one of the relatively small acalyptrate families belonging to the superfamily Opomyzoidea (sensu McAlpINE 1989); currently, the family is considered a sister group of the Opomyzidae (ROHÁČEK 1998, 2006, 2013; RoHÁČEK et al. 2019). There are 140 extant described species in the world (ROHÁčEK 2018) though many yet to be described. Larvae of these small slender flies are largely micro(phyto)saprophagous grazers of decayed or damaged tissues of graminoid plants usually 
occurring between the leaf base and stem. Other species can be associated with dicotyledonous plants by utilizing their soft rotting tissues as food, and only the species of the genus Fungomyza Roháček, 1999 have larvae developing in sporocarps of fungi (cf. ROHÁČEK 2006, 2009; ROHÁČEK \& BARBER 2011, 2016). However, for the Oriental and E. Palaearctic anthomyzids, biological information is almost absent (RoHÁČEK 2008, 2009, 2018; ROHÁČEK \& PRZHIBORO 2016).

Anthomyzids are also known from the areas surrounding Taiwan, including China (11 species of 5 genera) in the northwest, Japan ( 10 species of 4 genera) and the Korean peninsula (10 species of 5 genera) in the northeast and the Philippines (only one Amygdalops species recorded so far) in the south; for published data from these areas see SUEYOSHI \& ROHÁČEK (2003) and ROHÁČEK (2006, 2008, 2009, 2018). Considering this fact, it was expected that some of these taxa would also be found in Taiwan.

This study summarizes all available data on the Anthomyzidae occurring in Taiwan. Based on the previously published records (ROHÁČEK 2008) and the new (though relatively scanty) material under study, a total of 11 species representing two genera (Amygdalops and Anthomyza Fallén, 1810), has been confirmed in the country, including 8 species new to science. However, because of insufficient and/or poorly preserved material, only three of these species can be named and described below as "new species". Thus, contrary to expectation, no previously named species (including those known from adjacent countries) is added here as a new record from Taiwan.

\section{Material and methods}

Material. The material examined is deposited in collections as follows:

HNHM Hungarian Natural History Museum, Budapest (Hungary); NMNS National Museum of Natural Sciences, Taichung (Taiwan); NMPC National Museum, Praha (Czech Republic);

SIINH Saigusa Institute of Insect Natural History, Fukuoka, Japan; SMOC Silesian Museum, Opava (Czech Republic);

ZSMC Zoologische Staatsammlung München, München (Germany).

Methods. Specimens were examined, drawn and measured using two types of binocular stereoscopic microscopes (Reichert, Olympus SZX10). Male genitalia and female terminalia were examined after their detachment, maceration in hot $10 \% \mathrm{KOH}$, neutralization with $10 \%$ acetic acid, washing in water and dissection of the whole abdomen in a drop of glycerine under a binocular microscope. More detailed examination was performed with a compound microscope (JENAVAL). After examination, all parts were transferred to a small plastic tube in glycerine and pinned below the respective specimens.

Drawing techniques and photography. Legs were drawn on squared paper using a Reichert binocular microscope with an ocular screen. Details of the male and female terminalia were drawn using Abbe's drawing apparatus on a compound microscope (JENAVAL) at higher magnification $(130-350 \times)$. Wings were photographed on the compound microscope Olympus BX51 with an attached digital camera (Canon EOS 1200D). Whole adult (dry-mounted) specimens were photographed by means of a digital camera (Canon EOS 60D) with macro lens (Canon MP-E 65 mm 1-5×) and ring macro flash (Canon MR-14EX). The final images were edited in Adobe Photoshop CS6.

Measurements. Five main characteristics of adults were measured: body length (measured from anterior margin of head to end of cercus, thus excluding the antenna), wing length (from wing base to wing tip), wing width (maximum width), C-index $\left(\mathrm{Cs}_{3}: \mathrm{Cs}_{4}\right)$ (= ratio of length of 3rd costal sector : length of 4 th costal sector) and index r-m $\backslash \mathrm{dm}-\mathrm{cu}$ : $\mathrm{dm}-\mathrm{cu}$ (= ratio of length of section between $\mathrm{r}-\mathrm{m}$ and $\mathrm{dm}-\mathrm{cu}$ on discal cell : length of dm-cu). All type specimens were measured when represented by few specimens while in larger type series (more than 20 specimens) only 10 males and 10 females ( 3 largest, 3 smallest and 4 medium-length specimens of each sex) were measured.

Presentation of faunistic data. Label data of all specimens examined are presented strictly verbatim, those of primary types including information on colour of all associated labels. However, currently used transcriptions of geographical names and/or other geographical specification are given in square brackets. Phenological and other biological information obtained from the material examined and literature are given in the Biology paragraph; data on occurrence are summarized in the Distribution paragraph.

Morphological terminology follows that used in monographs of Anthomyzidae by RoHÁČEK (2006) and/or ROHÁČEK \& BARBER (2016) including terms of the male hypopygium and female terminalia. For male genitalia terminology, the "hinge" hypothesis of the origin of the eremoneuran hypopygium (see ZATWARNICKI 1996) has been adopted. The following synonymous terms of the male genitalia emanating from other hypotheses and used in recent manuals of Diptera (CUMmING \& WooD 2010, 2017) and/or the monograph of GRIFFITHS (1972) need to be listed (terms used here first): aedeagus = phallus; ejacapodeme $=$ ejaculatory apodeme; epandrium $=$ periandrium; gonostylus $=$ surstylus; medandrium $=$ bacilliform sclerite, intraepandrial or intraperiandrial sclerite; phallapodeme $=$ aedeagal apodeme; postgonite $=$ gonite, paramere. Morphological terms of the male postabdomen and genitalia are depicted in Figs 28, 32-39, those of the female postabdomen in Figs 40-47.

Abbreviations of morphological terms used in text and/ or figures

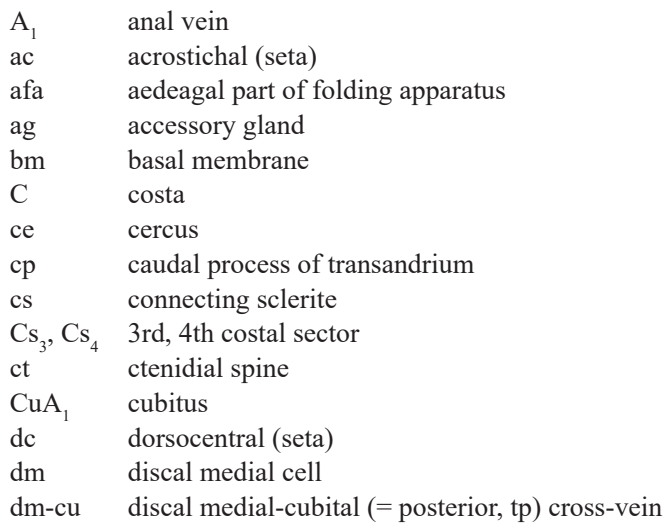




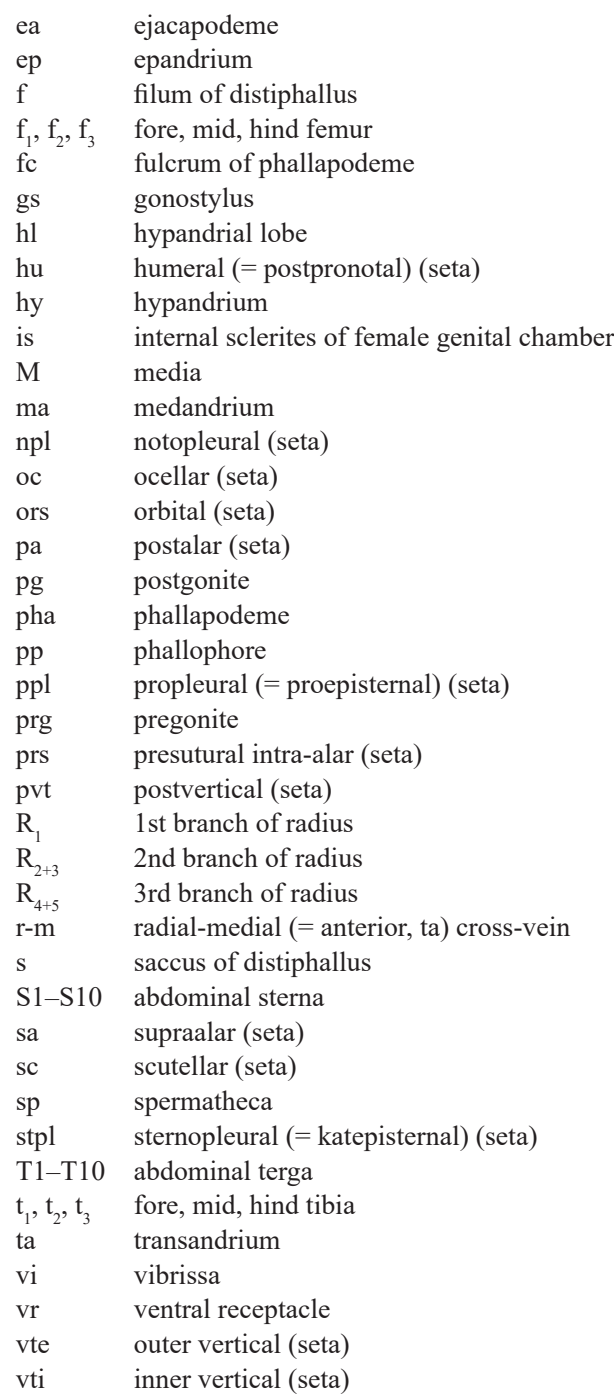

\section{Results}

\section{Genus Amygdalops Lamb, 1914}

Four species of this genus (one of them remaining unnamed) are the only representatives of Anthomyzidae previously recorded from Taiwan (RoHÁČEK 2008). One additional undescribed species has been found in the material under study and is briefly diagnosed at the end of this section. All these Taiwanese species of Amygdalops are keyed below.

\section{Amygdalops cuspidatus Roháček, 2008}

Published records. Three male paratypes were previously reported from Taipei City area (Nanshih Chiao, Han-LoDa) and Taichung City area (Ta Keng) by RoHÁČEK (2008: 345).

Biology. Most of the known specimens were swept from low herbaceous vegetation grazed by buffaloes (in Indonesia: Flores I.), others were netted from forest undergrowth; adults were found in February, September and October (ROHÁČEK 2008).

Distribution. An Oriental species but as yet known only from Taiwan (Taipei City area, Taichung City area) and Indonesia (Flores, Java), see RoHÁčEK (2008).

\section{Amygdalops sp. nov. near cuspidatus}

Published records. The only known record from Taiwan is a single female from Taichung City area (Ma-Chu-Ken river valley). This relative of Am. cuspidatus Roháček, 2008 remains unnamed because of insufficient material but a detailed description of the female was previously published (ROHÁČEK 2008: 349).

Biology. Unknown. The only known female was collected in a river valley in April (ROHÁČEK 2008).

Distribution. Only known from Taiwan (Taichung City area), see RoHÁČEK (2008).

\section{Amygdalops curtisi Roháček, 2008}

Published records. Recorded on the basis of one male and one female paratype from Kinmen County (Thunghsiao, Miaoli) and Taichung City area (Tachia Hsi river) by RoHÁČEK (2008: 352).

Biology. Adults were collected at a light or swept along a forest brook, in March, May, June, and October to December (RoHÁČEK 2008).

Distribution. An Oriental species known from Taiwan (Kinmen County, Taichung City area) and Thailand (RoHÁČEK 2008).

\section{Amygdalops nigrinotum Sueyoshi \& Roháček, 2003}

Material examined. TAIWAN: Chiayi County, Meishan Township (cl. to Alishan), No. 75, Youyelin, De Ren Tea Gardens [at Ruili], 23 $32^{\prime} 14.4^{\prime \prime}$ N 12040'19.6" E, 960 m, at light, 1.v.2019, 1 ô, M. Tkoč leg. (NMPC, genit. prep.).

Published records. Previously recorded from Taiwan by RoHÁČEK (2008: 364) from Kaohsiung County (Liukuei) and Changhua County (Tatu).

Biology. Adults of this common species were collected from herbaceous vegetation of a creek valley grazed by buffaloes (over 150 specimens), at brooks and rivers in various forests and in light traps, from January to December (ROHÁČEK 2008).

Distribution. A widespread, originally Oriental species that expanded its range to eastern Afrotropical (Seychelles), northern Australian (Queensland), eastern Palaearctic (Japan) and Oceanian (Hawaii) Regions, cf. RoHÁČEK (2008). In Taiwan known from Changhua, Chiayi, and Kaohsiung Counties.

\section{Amygdalops sp. nov. near curtistylus}

Material examined. TAIWAN: Fuchien chinmen [= Kinmen County, on Kinmen Is. neighbouring with continental China], sweeping net, 17.-20. viii.1999, 1 + , C. S. Lin leg. (NMNS, genit. prep.); Nantou [County]: Puli Taiyi Farm, sweeping net, 16.xi.2001, 1 †, C. S. Lin leg. (NMNS).

Diagnosis. This undescribed species seems to be most closely related to Am. curtistylus Roháček, 2008 considering the similarly formed structures of the 7 th segment of the female abdomen. Very dark species, with frons entirely brown. Frontal triangle long, reaching to anterior fourth of frons, anteriorly tapered. Orbits and frontal triangle (including ocellar triangle) glabrous and shiny but stripes between them densely dark-grey microtomentose and dull. 
Palpus ochreous, brown apically. Antenna unusually dark, brown. Legs, wing pattern and haltere as in Am. curtistylus. Discussion. This species remains unnamed because of insufficient ( 2 females) and poorly preserved material. It belongs to the Am. nigrinotum group (as defined by RoHÁČEK 2008: 345) and most closely resembles the yellow -legged species of this group. It would run to couplet 11 in the key of RoHÁČEK (2008: 393) but differs from both species placed here (Am. curtistylus and Am. pappi Roháček, 2008) as well as from other members of this group by the distinctly brown antennae and the structure of the female 7 th sternum. The full description and naming of this species awaits additional, better-preserved specimens of both sexes to become available for study.

Biology. Unknown. The two females examined were swept in August and November.

Distribution. Taiwan (Kinmen and Nantou Counties).

\section{A preliminary key for the identification of the Taiwanese species of Amygdalops}

1 Wing with preapical brown spot confluent with distinct darkened stripe along $\mathrm{R}_{4+5}$ (see ROHÁčEK 2008: figs 164-165).

- Wing with only preapical brown spot, otherwise uniformly pale-pigmented (see RoHÁčEK 2008: figs 166-170).

2(1) Frons anteriorly (at ptilinal suture) pale yellow; frontal triangle reaching to anterior third of frons. Palpus yellow. Anterior dc reduced, only twice the length of dc microsetae. Male with elongate, slender and apically tapered gonostylus (RoHÁčEK 2008: fig. 43) and distinctive transandrium (RоHÁČEK 2008: fig. 41) with dorsomedial arched sclerite. Female S6 narrow (RoHáčEK 2008: fig. 47), T7 anteriorly with pale-pigmented crescent-shaped area (RoHÁčEK 2008: fig. 45) and S7 small, tapered anteriorly and simply pigmented (RoHÁčEK 2008: fig. 47).

Am. cuspidatus Roháček, 2008

Frons anteriorly pale brown; frontal triangle short, reaching only to half of frons. Palpus pale brown with darkened apex. Anterior dc distinct, about half the length of posterior dc. Male unknown. Female S6 broad, transverse and largely brown (RoHÁčEK 2008: fig. 54), T7 simply dark-pigmented (ROHÁČEK 2008: fig. 53) and S7 larger, having dark anterior tapered part with narrow unpigmented medial area (ROHÁČEK 2008: fig. 54).

Am. sp. n. near cuspidatus

3(1) Palpus ochreous with brown apex. Antenna entirely brown. ......................... Am. sp. nov. near curtistylus Palpus yellow to orange. Antenna yellow to yellowish ochreous, at most somewhat darkened on dorsal side of pedicel and around base of arista. ... 4

4(3) vti markedly shorter and weaker than (often less than half the length of) vte. Male $f_{3}$ with only 5 thickened and shortened setae in posteroventral row. Gonostylus large and broad also apically (RoHÁČEK 2008: figs 60, 62); caudal process broad, ventrally forked (RoHÁČEK 2008: fig. 58); basal sclerite of postgonite small. Anterolateral corners of female T7 extended on ventral side and almost meeting medially; S7 small, anteriorly tapered (RoHÁčEK 2008: fig. 67); spermathecae spherical, large (RонÁČEK 2008: fig. 65). ......... Am. curtisi Roháček, 2008 vti longer, about two-thirds of vte length. Male $f_{3}$ with 7-8 thickened and shortened setae in posteroventral row. Gonostylus distally tapered (RонÁČEK 2008: figs 100, 103); caudal process formed by 2 sclerites, each having a lateral projection (RoHÁČEK 2008: fig. 101); postgonite with large basal sclerite (RoHÁČEK 2008: fig. 104). Anterolateral corners of female T7 not extended ventromedially and S7 anteriorly wider than posteriorly (ROHÁČEK 2008: fig. 106); spermathecae shortly pyriform and small (RоHÁČEK 2008: fig. 107).

Am. nigrinotum Sueyoshi \& Roháček, 2003

\section{Genus Anthomyza Fallén, 1810}

No species of this largely Holarctic genus has previously been recorded from Taiwan. However, the genus is probably well represented, particularly in montane areas of the country. Interestingly, of the 6 species recorded below, only $A$. robusta belongs to the $A$. bellatrix group, while as many as five species belong to the A. flavosterna group (established here below). The species richness of the latter group in Taiwan is peculiar inasmuch as this group otherwise only includes the E. Palaearctic species A. flavosterna Sueyoshi \& Roháček, 2003. Because of their occurrence in high-montane habitats, it is highly probable that most or even all these newly reported species are endemic to Taiwan. If this proves to be true then the Alavosterna group could have its centre of diversity on this island.

\section{The Anthomyza bellatrix group}

The group was first delimited by RoHÁčEK (2006: 171) and characterized by the following synapomorphies: head with a pair of whitish grey microtomentose stripes on occiput; thoracic macrosetae long but thin; scutellum dorsally flattened; male $\mathrm{f}_{3}$ with a row of shortened thickened posteroventral setae; basal fork of phallapodeme strongly asymmetrical; aedeagal part of folding apparatus with robust internal spines; filum of distiphallus with conspicuously dilated apex having 2 or 3 projections; ejacapodeme strongly reduced; female tergosternum $\mathrm{T} 7+\mathrm{S} 7$ dorsally short; female S8 shortened; internal sclerites of female genital chamber (comprising 2 pairs of posterior sclerites and 1 annular sclerite) complex and more or less asymmetrical, with annular sclerite elongate. All previous phylogenetical hypotheses (morphological - RoHÁČEK 2009: fig. 141; ROHÁČEK \& BARBER 2016: fig. 605; molecular - ROHÁČEK \& TóTHOvá 2014: fig. 1; RoHÁČEK et al. 2019: figs 2, 4) recognized $A$. bellatrix group as distinct monophyletic lineage but its relationships to other groups of Anthomyza remains to be resolved (cf. RoHÁČEK et al. 2019). The group seems to be restricted to eastern Asia and includes the following species: A. cuneata Roháček, 1987 (Nepal, China, most ancestral species), A. bellatrix 
Roháček, 1984 (North Korea, Japan, Russia: Kuril Is.), $A$. trifurca Sueyoshi \& Roháček, 2003 (China, North Korea, South Korea, Japan) and A. robusta sp. nov. (Taiwan) described below.

\section{Anthomyza robusta sp. nov.}

\author{
(Figs 1, 4-21)
}

Type material. HоLOTYPE: 0 , labelled: "TAIWAN, Ali-shan [= Alishan], May 25, 1971, K. Kanmiya leg." (handwritten) and "Holotypus Anthomyza robusta sp. n., J. Roháček det. 2019” (red label, printed). The specimen is intact, dry mounted on a pinned triangular card (SMOC). PARATYPES: 1 10 10 , with same label data as for the holotype, only second (type) label is yellow with "Paratypus" (SMOC, 1 o 1 genit. prep.). Other paratypes: TAIWAN: [Chiayi County]: Mt. Alishan [= Alishan], 26.v.1971, 2 우 (1 genit. prep.); same locality, 2200 m, 1.xi.1985, 1 , all K. Kanmiya leg. (SMOC); Chiayi Hsien [= Chiayi County]: Alishan, $2300 \mathrm{~m}, 8 . \mathrm{iv} \cdot 1965,3$ o 3 q $(1) 1$ q genit. prep., 1 with wing removed and preserved with genit. prep.), 9.iv.1965, 201 , all T. Saigusa leg. (SIINH); Alishan Shamno (mountains), end of road from Chiayi, $23,28 \mathrm{~N} 120,48 \mathrm{E}$ [ $\left.=23^{\circ} 28^{\prime} \mathrm{N} 120^{\circ} 48^{\prime} \mathrm{E}\right], 2000 \mathrm{~m}$, pasture near park, surrounded by wood, swept, eclector, 11.iii.1994 (No. X 941), 1 ô,
Kung-ju Lin leg. (ZSMC, dried from ethanol); Nantou Hsien [= Nantou County]: Tungpu [= Donpu], Lulinshan, 10.iv.1965, 1 §ै, T. Saigusa leg. (SIINH); Nantou [County]: Nanhuashan, sweeping net, 6.v.1992, 2 4 우, Yang \& Huang leg. (NMNS, 1 genit. prep.); Nantou [County] Meifeng, sweeping net, 27.ii.1992, 1 Oै, Y. C. Shiau leg. (NMNS); Nantou [County]: Yunahaipaohsienso [24.046602 N, 121.236046 E], sweeping net, 4.v.1992, 1 §, W. T. Yang leg. (NMNS); Nantou [County]: Kahoerhshan, sweeping net, 7.v.1992, 1 1 1 , W. T. Yang leg. (NMNS, 1 q genit. prep.); Nantou County: Ren'ai Township, $3 \mathrm{~km} \mathrm{~S}$ of Lishan, Fushoushan, camping site, $24^{\circ} 13^{\prime} 15^{\prime \prime} \mathrm{N} 121^{\circ} 14^{\prime} 20^{\prime \prime} \mathrm{E}, 2560 \mathrm{~m}$, sweeping vegetation, 12.v.2018, 2 을. M. Tkoč leg. (NMPC, NMNS, 1 genit. prep.); Nantou County: Hohuachi, Lishan-Tayuling, road no. 8, $24^{\circ} 13^{\prime} \mathrm{N} 121^{\circ} 16^{\prime} \mathrm{E}, 1950$ m, 31.iii.2000, 1 \%, L. Peregovits \& A. Kun leg. (HNHM).

Description. Male. Total body length $2.30-2.58 \mathrm{~mm}$; general colour dark brown, densely grey microtomentose, dull (Fig. 4).

Head about as long as high, with indistinctly projecting frons and somewhat receding face but rounded anteriorly in profile. Occiput dorsomedially concave, blackish brown, medially with a pair of silvery whitish-grey microtomentose stripes (cf. Fig. 5) coalescing dorsally (sometimes also

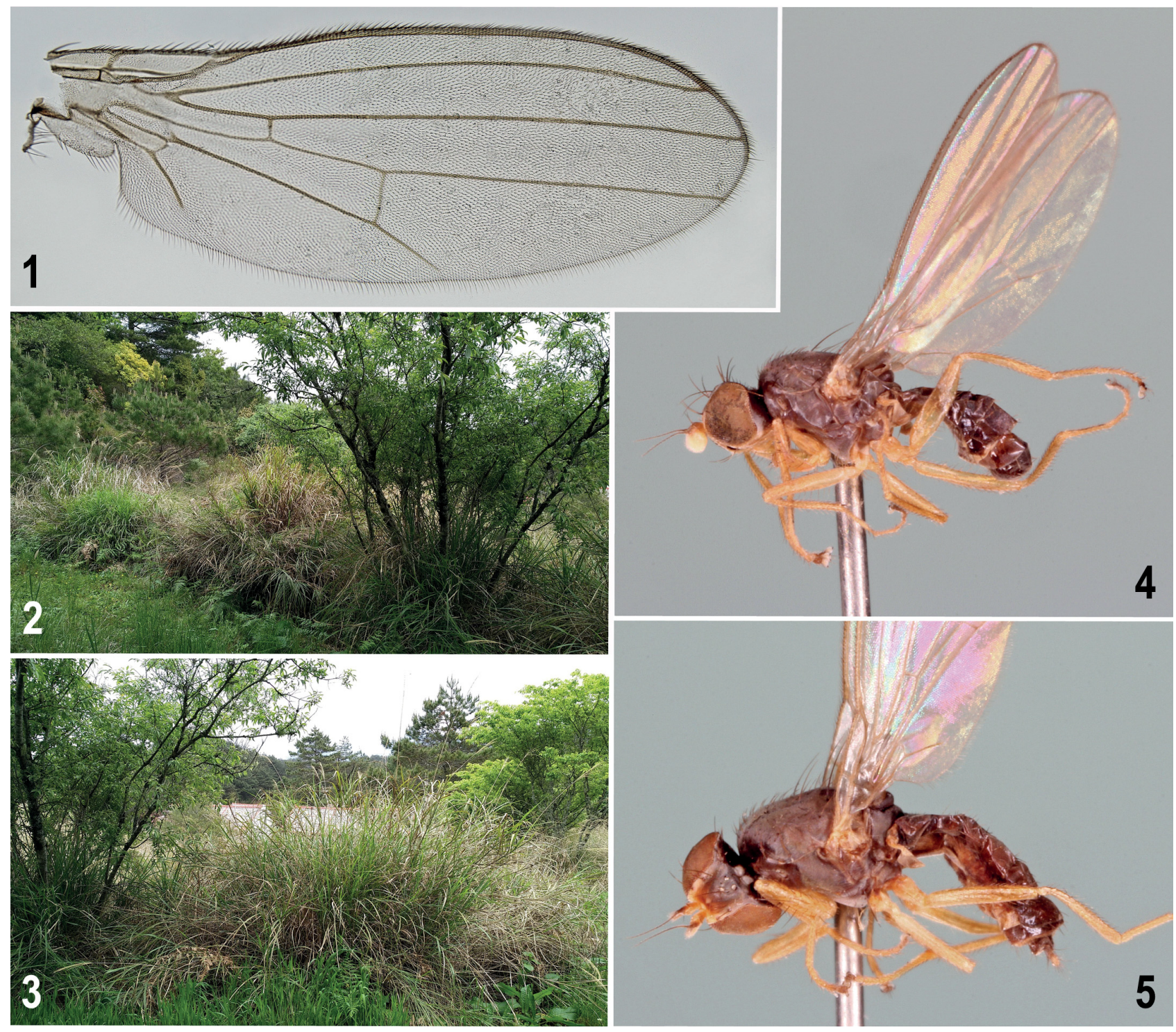

Figs 1-5. Anthomyza robusta sp. nov. and its habitat in Taiwan. 1 - wing, male paratype (length ca. $2.7 \mathrm{~mm}$ ); 2 - grasses at margin of montane forest in Fushoushan (Nantou County), habitat of the species; 3 - detail with a tussock of grass, Miscanthus sinensis, probable host plant; 4 - male paratype from Alishan Mt., laterally (Chiayi County), body length ca. $2.5 \mathrm{~mm} ; 5$ - female paratype from the same locality, laterally, body length ca. $3.1 \mathrm{~mm}$. Photos by M. Tkoč $(2,3)$ and J. Roháček (others). 
ventrally) and reaching from ocellar triangle to foramen. Frons darker than in A. trifurca, dark yellow or orange only in anterior fourth (lightest on orbits), frontal (including ocellar) triangle dark brown to brown (only anterior corner) and pale-grey microtomentose; stripes between frontal triangle and orbits brown to (anteriorly) pale brown, distinctly dark striated and often reaching as far as anterior margin of frons (cf. Fig. 5). Orbits dark yellow only anteriorly (up to anterior long ors) and becoming darker (brown) posteriorly, sparsely whitish microtomentose up to posterior ors, grey microtomentose beyond it. Frontal triangle large and broad, with acute anterior corner reaching to anterior fifth or sixth of frons. Frontal lunule distinct, yellow. Face narrow, weakly sclerotized medially and narrowly depressed, dull yellow and whitish microtomentose; parafacialia and gena pale yellow and silvery-white microtomentose, both bordered by broad ochreous to pale-brown marginal stripe; postgena dark brown, narrowly yellow ventrally, whitish-grey microtomentose; mouthparts dark ochreous except for yellow palpus. Cephalic chaetotaxy as in A. trifurca: pvt relatively long and strongly crossed; vti and oc subequal, longest of cephalic setae; vte and posterior ors slightly shorter than vti; 2 long ors, anterior somewhat shorter than posterior; 1 microsetula (only as long as medial microsetulae) in front of anterior ors; 1 pair (rarely 2 pairs) of medial microsetulae near anterior margin of frons; 1 proclinate setula behind vte distinctly longer than uppermost postocular; 6 or 7 postocular setulae, in single row; postgena with small setulae, and 1 or 2 relatively short posteroventral setae; $1 \mathrm{vi}$, about as long as anterior ors; subvibrissa reduced, weak, slightly longer than very fine and sparse (3-4) peristomal setulae. Palpus elongate, yellow, with 1 dark preapical seta and 3 ventral setulae. Eye large, broadly ovoid, narrower posterodorsally, with longest diameter slightly oblique and about 1.2-1.3 times as long as shortest. Shortest genal height about $0.14-0.16$ times as long as shortest eye diameter. Antenna with orange-ochreous scape and pedicel; 1st flagellomere whitish yellow, but ochreous-brown around insertion of arista, with short, white pilosity on anteroventral margin. Arista dark brown, 1.9-2.0 times as long as antenna, with distinctly thickened basal segment and short, dark ciliation.

Thorax very slightly narrower than head, brown to blackish brown, dull due to dense pale-grey microtomentum (Figs 4, 5), often with a bluish tinge; apical margin of scutellum, postalar callus and sutures between pleural sclerites usually paler brown. Thoracic chaetotaxy: $1 \mathrm{hu}$, longer than posterior $\mathrm{npl} ; 2 \mathrm{npl}$ (anterior longer); 1 prs (relatively long, as long as hu); 1 sa (as long as prs); 1 longer pa; 2 long postsutural dc (anterior shorter than posterior) and 6-7 dc microsetae in front of them; 4 rows of ac microsetae at level of suture but only 2 medial rows more posteriorly, these reaching (usually as single setula) to the level of posterior dc; $2 \mathrm{sc}$, laterobasal very weak, shorter than sa, apical as long as posterior dc (longest thoracic setae); 1 small but distinct, upcurved ppl; 2 stpl, anterior somewhat shorter, 2 or 3 setulae below the latter; ventral part of sternopleuron with 3 or 4 longer, paler setae. Scutellum rounded triangular, flat dorsally. Legs light yellow, only distal half of last tarsal segment of all tarsi brownish. $\mathrm{f}_{1}$ with ctenidial spine only slightly shorter than maximum width of $\mathrm{t}_{1}$, longer than that of $A$. trifurca; $\mathrm{f}_{2}$ with posteroventral row of sparse, fine but long, erect setae; $f_{3}$ with posteroventral row of setae but only a few (2-4) in apical third, thickened and shortened; $t_{2}$ with short (although longer than maximum width of $t_{2}$ ) ventroapical seta; $t_{1}, t_{3}$ and all tarsi simply setulose but fore and hind basitarsus with 2 or 3 ventral proximal setulae prolonged, less so on hind basitarsus. Wing (Fig. 1) long but not very narrow, with pale-brown veins and pale-brown hyaline membrane. $\mathrm{C}$ with sparse and short spinulae between apices of $\mathrm{R}_{1}$ and $\mathrm{R}_{2+3}$. $\mathrm{R}_{2+3}$ long, bent parallel to $\mathrm{C}$, with apex very slightly upcurving; $\mathrm{R}_{4+5}$ very slightly bent to straight, subparallel to $\mathrm{M}$ apically. Cell $\mathrm{dm}$ with $\mathrm{r}-\mathrm{m}$ situated slightly in front of its middle. Apical portion of $\mathrm{CuA}_{1}$ slightly longer than $\mathrm{dm}$-cu but not reaching wing margin; $\mathrm{A}_{1}$ short, ending far from margin. Alula small, well developed. Wing measurements: length 2.54-2.94 mm, width 0.85-0.97 mm, $\mathrm{Cs}_{3}$ : $\mathrm{Cs}_{4}=0.90-1.17, \mathrm{r}-\mathrm{m} \backslash \mathrm{dm}-\mathrm{cu}: \mathrm{dm}-\mathrm{cu}=2.20-2.62$. Haltere with yellow stem and pale brown knob.

Abdomen. Preabdominal terga brown to blackish brown, with sparse grey or greyish-brown microtomentum, subshining. T1 shorter and narrower than T2, fused together only laterally; T2-T5 subequal in length, broad, each with sparse but relatively strong setae. Preabdominal sterna pale brown, with sparse fine setae, narrow anteriorly but becoming markedly wider posteriorly; S2 and S3 longer than wide, S4 slightly wider than long. S5 largest preabdominal sternum, much wider than long, transversely crescent-shaped, with strongly concave posterior margin. T6 short, transverse, membranous and entirely unpigmented. Synsternum S6-S8 dark brown, situated left laterodorsally, strongly asymmetrical and strikingly bulging on left side due to unusually convex S7. S6 larger than usual, as long as S7, with thick, strongly sclerotized and sinuous anterior ledge projecting onto ventral side and dorsally fused with that of S7. S6 with 2, S7 with 2-4 short setae. S8 longer than $\mathrm{S} 7$, longest on its right side and sparsely setose in posterior half.

Genitalia. Epandrium (Figs 6, 7) of moderate size, slightly broader than high, with rather sparse setae including 2 pairs of longer setae; anal fissure small, subtriangular, more acute dorsally than in A. trifurca. Cercus relatively short and narrow, finely micropubescent and setose, with apical and preapical setae longest. Medandrium (Fig. 6) of moderate size, subquadrate, ventrally as broad as dorsally, with dorsolateral corners more projecting than that of $A$. trifurca. Gonostylus (Figs 6, 7, 10) most closely resembling that of $A$. trifurca but broader, with posterior marginal outline distinctly convex and with posteroventral corner blunter; micropubescent on almost entire outer side and setose on inner side. Hypandrium (Fig. 11) relatively robust and broad (in dorsal view), with leaf-like anterior internal lobes (Fig. 11, hl) but differing from that of $A$. trifurca by the more expanded, fan-like anterior marginal part. Transandrium (Fig. 12) closely resembling that of A. trifurca but with distinct, short and broad caudal process coalescing ventrally with basal membrane. Pregonites 
distinctly asymmetrical: left pregonite (Fig. 11) with two large, ventrally protruding lobes; anterior lobe triangular (not rounded, lobate as in $A$. trifurca) with 3 medial setae, and posterior lobe subequally long, also triangular but more acute, usually with 6 setae on anterior margin; in contrast, right pregonite with posterior lobe low, projecting little ventrally. Postgonite (Fig. 11) relatively short but somewhat larger than in A. trifurca and slightly sinuate, with apex rounded and 1 anterior setula situated in the middle of anterior margin. Basal membrane densely, almost regularly spinose, but spinose area not as broad as in A. trifurca (Figs $11,12)$. Aedeagal part of folding apparatus with pale wart-

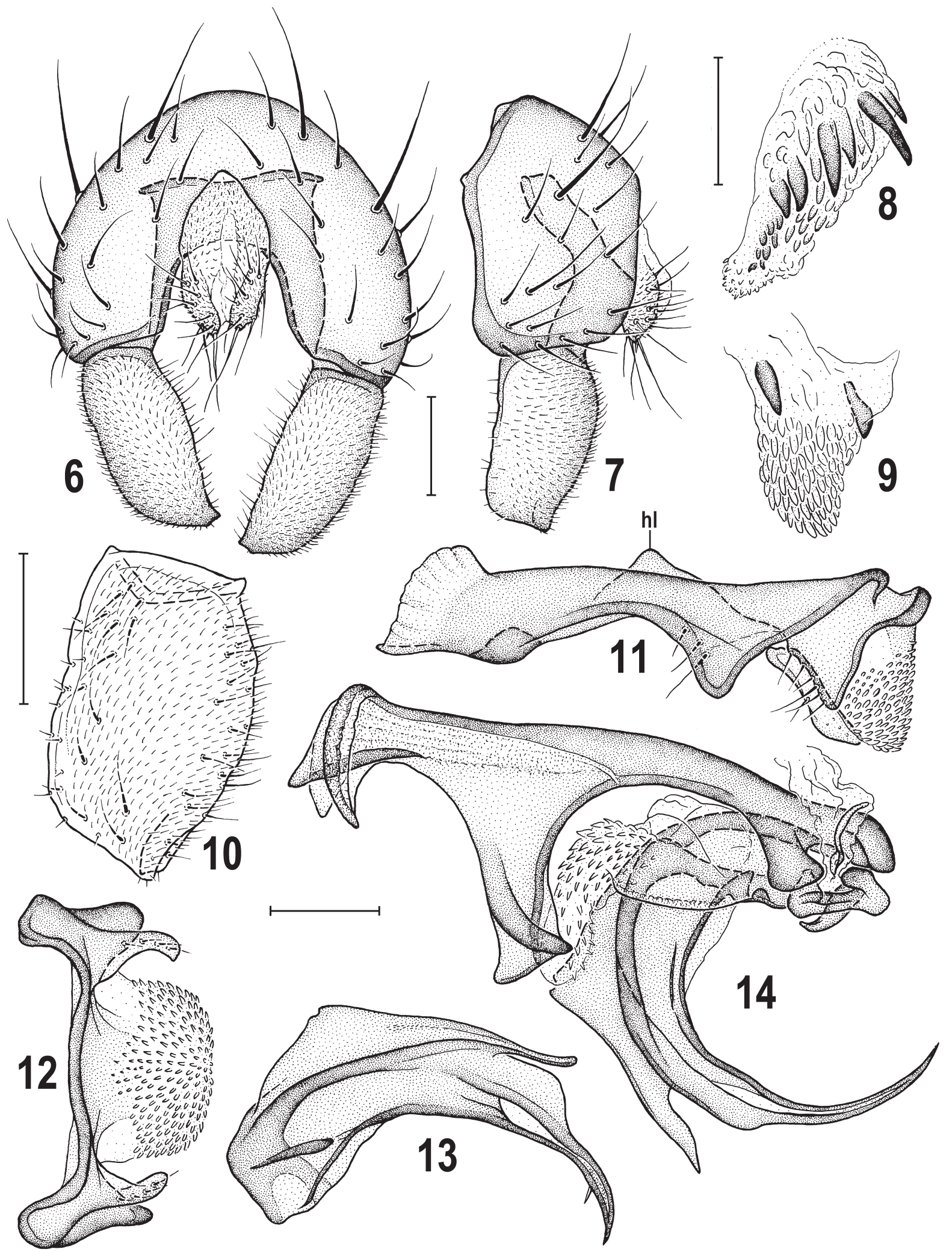

Figs 6-14. Anthomyza robusta sp. nov., male paratype. 6 - external genitalia, caudally; 7 -the same, laterally; 8 - right wall of aedeagal part of folding apparatus; 9 - left wall of the same; 10 - gonostylus, lateroventrocaudally (widest extension); 11 - hypandrial complex, laterally; 12 - transandrium, caudally; 13 - filum of distiphallus, ventrally; 14 - aedeagal complex, laterally. All scales $=0.1 \mathrm{~mm}$. For abbreviations see pp. $270-271$. 
like excrescences and 2 robust dark spines on left side (Fig. 9) but with more pigmented spines (4 or 5 large and others shorter and paler) and a series of subterminal short dark blunt spines or tubercles on right side (see Fig. 8). Connecting sclerite membranous, hardly visible, not illustrated in Fig. 14. Phallapodeme robust including fulcrum, basally asymmetrical as in $A$. trifurca, with apex tricuspid (Fig. 14), with middle part somewhat projecting, in addition to lateral, wing-like projections. Aedeagus with small, short phallophore (Fig. 14) having ventral claw-like sclerite as in A. trifurca. Distiphallus huge, broad including basally where fused with phallophore. Saccus short, smaller than

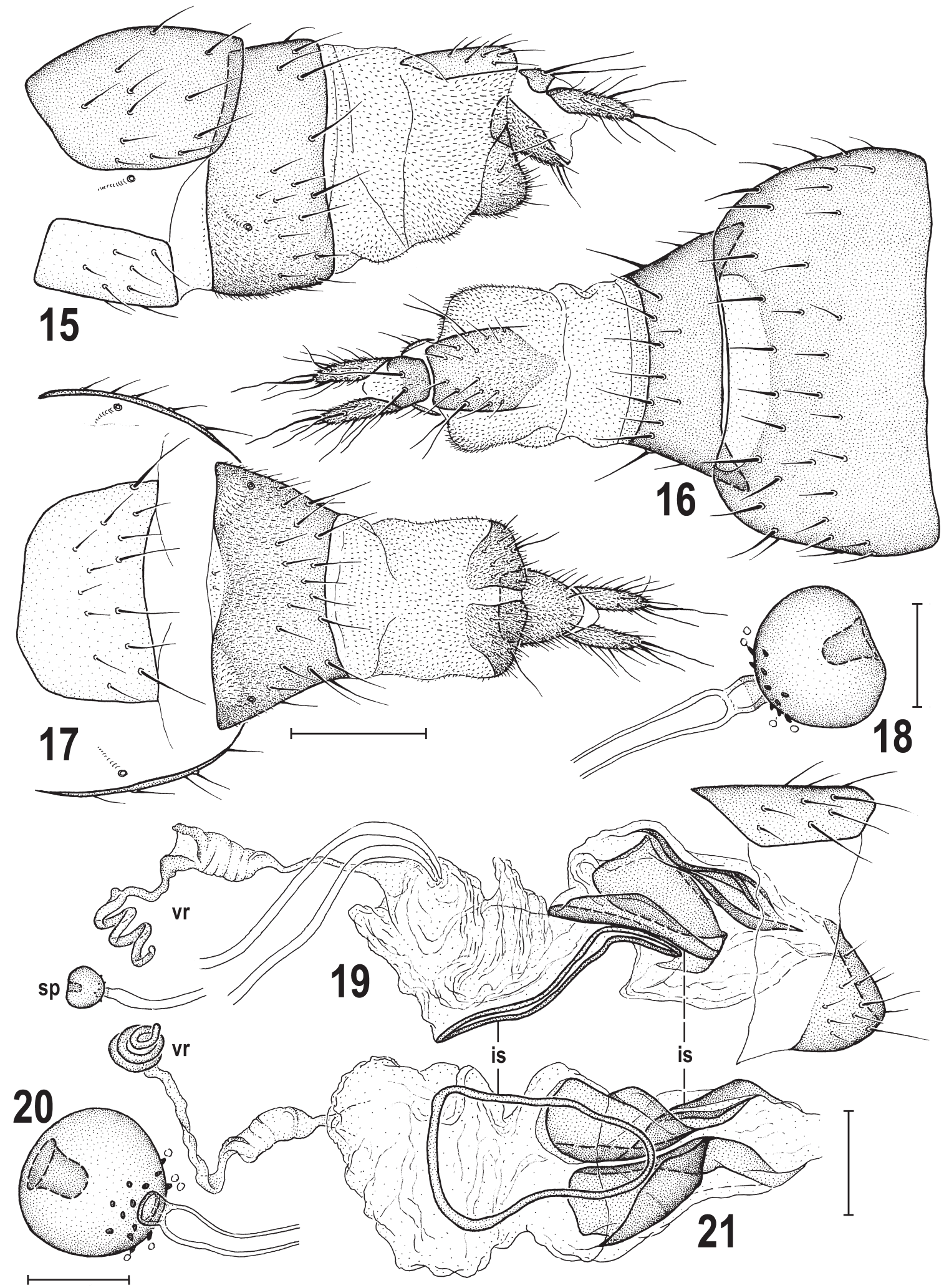

Figs 15-21. Anthomyza robusta sp. nov., female paratype. 15 - postabdomen, laterally; 16 - the same, dorsally; 17 -the same, ventrally; 18 - spermatheca; 19 - genital chamber with 8th abdominal segment, laterally; 20 - spermatheca; 21 - genital chamber, ventrally. Scales $=0.2 \mathrm{~mm}$ (Figs $15-17), 0.03 \mathrm{~mm}$ (Figs 18, 20) and $0.1 \mathrm{~mm}$ (others). For abbreviations see pp. 270-271. 
in A. trifurca, largely overgrown by short unpigmented spines. Filum extremely robust and formed by single complex sclerite as in A. trifurca but markedly wider in middle and terminating in only 2 peculiar projections: 1 very long, slender, curved and pointed (formed by fusion of two very slender processes), directed posteriorly and bearing 1 distinct spine (only visible in ventral view, Fig. 13) and 1 shorter, blade-shaped and directed posteroventrally (see Fig. 14). Ejacapodeme very slender, similar to that of $A$. trifurca, also partly hidden in phallapodemal fork (Fig. 14).

Female (Fig. 5). Similar to male unless mentioned otherwise. Total body length $2.58-3.14 \mathrm{~mm}$. Antenna with 1st flagellomere pale brownish on both outer and inner sides, yellow only along proximal and ventral margin. $f_{2}$ and $\mathrm{f}_{3}$ simply setulose, with setae in posteroventral rows shorter, not erect or thickened. Last segments of all tarsi usually entirely brownish. Wing measurements: length 3.05-3.61 mm, width 0.99-1.23 mm, $\mathrm{Cs}_{3}: \mathrm{Cs}_{4}=0.90-1.12$, $\mathrm{r}-\mathrm{m} \backslash \mathrm{dm}-\mathrm{cu}: \mathrm{dm}-\mathrm{cu}=1.91-2.50$. Abdomen wider, with T1-T5 more transverse than in male. Preabdominal sterna narrow (pleural membranous part of segments large), pale ochreous, only S1 (short and transverse) and S2 brown; S3 and S4 somewhat longer than wide, becoming wider posteriorly; S5 distinctly wider than long, trapezoidal, posteriorly widened.

Postabdomen (Figs 15-17) somewhat longer and more tapered from 7th segment than in A. trifurca. T6 large and long, almost as broad as T5, dark brown but with unique pale-pigmented, transverse and bare medial area in posterior fourth (Fig. 16). S6 larger and wider than S5, transversely subtrapezoidal, wider posteriorly, pale ochreous (Fig. 17). Tergosternum $\mathrm{T} 7+\mathrm{S} 7$ also different from that of $A$. trifurca, dorsomedial length shortest, but uniformly blackish brown both dorsally and laterally (Figs 15, 16); ventral part (Fig. 17) also dark, paler-brown pigmented only narrowly anteriorly (around medial basal sensilla, out to spiracles) and with longer micropubescence in anterior two thirds, setose in posterior half. 8th segment (Fig. 15) largely membranous and densely micropubescent. T8 longer and narrower than in A. trifurca, with brown pigmentation tapered anteriorly, and lacking defined anterior margin, i.e. not separated from intersegmental membrane. S8 much shorter (although somewhat longer that that of $A$. trifurca) than T8, divided medially into 2 brown-pigmented sclerites each posteriorly bent dorsally. Genital chamber with complex and asymmetrical internal sclerites (Figs 19, 21 , is) closely resembling those of $A$. trifurca, but 2 pairs of partly fused and crooked posterior sclerites longer, without ventral extension (Fig. 19) and medial annular sclerite slender, longer and anteriorly wider than in A. trifurca, located mostly anterior to the paired sclerites (Figs 19, 21). Ventral receptacle (Figs 19, 21) long, tube-like, hyaline, spirally coiled distally; its duct proximally slender but widened in the middle, thus very similar to that of $A$. trifurca; remnants of accessory gland not observed (presumably very small as in other members of the $A$. bellatrix group, cf. ROHÁČEK 2006). Spermathecae (1+1) subspherical (Figs 18, 20), with distinct but relatively short terminal invagination, plain surface (without transverse striae), dark tuberculi- form spines surrounding duct insertion and small, partly pale-brown pigmented cervix. T10 small, narrow and short, dark-pigmented (Fig. 16), with single medial pair of long setae and reduced micropubescence. S10 (Fig. 17) narrow but longer than T10, brown, finely micropubescent and setulose as in $A$. trifurca. Cercus long and slender (Figs $15,16)$, with apical and dorsopreapical setae as long as cercus, closely resembling that of $A$. trifurca.

Discussion. Anthomyza robusta sp. nov. belongs to the $A$. bellatrix group (as defined by RoHÁČEK 2006: 171) consisting of only E. Asian taxa. The phylogenetic relationships of this distinctive group of Anthomyza has hitherto not been unambiguously resolved (cf. ROHÁčEK \& BARBER 2016, RoHÁČEK et al. 2019) but it could be allied to some species described recently from China (ROHÁČEK 2018). Nevertheless, this new Taiwanese species is clearly the closest relative of the E. Palaearctic $A$. trifurca which is also known from adjacent mainland China (ROHÁČEK 2018). The next most closely allied species is the E. Palaearctic A. bellatrix Roháček, 1984, which thus represents the sister species to this pair (cf. ROHÁČEK \& BARBER 2016: 379, fig. 605). The sister-species relationship of $A$. robusta sp. nov. and $A$. trifurca is demonstrated by a number of synapomorphies, particularly in the male terminalia (phallophore with ventral claw-like sclerite; pregonites deeply bilobed and asymmetrical; saccus reduced but spinose; filum huge, broad also in proximal half and with long terminal projections). The two species also resemble each other externally including the form of the head, colouration of the frons, chaetotaxies and wing venation.

Anthomyza robusta sp. nov. can be confidently distinguished from $A$. trifurca by the following features: more robust body; distinctly darker frons (yellow restricted to anterior fourth of frons, dark stripes almost reaching anterior margin of frons); $f_{1}$ with ctenidial spine longer; male $\mathrm{f}_{3}$ with only a few (2-4) thickened setae in apical third of posteroventral row; male S5 transversely crescent-shaped, with concave posterior margin; male synsternum S6-S8 strikingly bulging on left side due to unusually convex S7; gonostylus broader, with posterior outline distinctly convex and with posteroventral corner blunt; anterior lobe of left pregonite subtriangular; saccus small and largely covered by short unpigmented spines; filum much broader in the middle and its apex with only 2 main projections (the longer bearing a spine); female T6 with distinctive posterior transverse, bare and pale medial area; female T7+S7 entirely blackish brown dorsally; T8 elongate, narrower, brown but with pigmentation tapered anteriorly; all internal sclerites of female genital chamber longer; spermathecae $(1+1)$ subspherical, with plain surface but with some tuberculiform spines. For further differences see above description.

Etymology. The name (robustus = robust, strong, Latin adjective) of this new species reflects the fact that it has a more robust body and male postabdomen than its closest relative, $A$. trifurca.

Biology. The biological data obtained from the type material are very limited, comprising only phenological and altitude information. However, thanks to M. Tkoč who 
collected the most recent series of specimens of $A$. robusta sp. nov. in Fushoushan (Nantou County), we know that the species is here associated with tussocks of the large grass Miscanthus sinensis Andersson (identified by D. Zelený) on the margins of montane forest (see Figs 2, 3). According to D. Zelený (personal communication, 2019), this grass is widespread in Taiwan, occurring from lowlands to high mountains, not only in natural but also in secondary successional or disturbed habitats. Considering this fact, it is interesting that $A$. robusta has so far been found only at high altitudes (1950-2560 m). Adults were collected by sweeping vegetation in February to May (most specimens in May), and November.

Distribution. Taiwan: Chiayi and Nantou Counties.

\section{The Anthomyza flavosterna group (new group)}

This new group is established here for Anthomyza flavosterna and five species new to science from Taiwan, i.e. Anthomyza caesarea sp. nov. and A. elongata sp. nov. described below, and three additional unnamed species, $A$. sp. nov. near elongata, $A$. sp. nov. (1) near flavosterna and $A$. sp. nov. (2) near flavosterna. The group is characterized as follows: head distinctly angular in profile; vti very long (by far the longest cephalic seta); 3 relatively weak ors becoming shorter anteriorly; thorax sparsely grey microtomentose and relatively shining; sternopleuron more or less (at least its ventral corner) yellow; $\mathrm{f}_{1}$ with very short ctenidial spine; male $\mathrm{f}_{2}$ and $\mathrm{f}_{3}$ with posteroventral row of fine erect setae, some in distal third of $\mathrm{f}_{3}$ shortened and thickened; male cercus relatively small; epandrium with anal fissure small; pregonite low, projecting little ventrally, with anterior and posterior clusters of long setae; postgonite without seta or setula; base of slender phallapodeme symmetrical; phallophore elongate; saccus small, with dense short spines; filum very robust and expanded distally, with finely tuberculate surface and slender, characteristically projecting apex; female $\mathrm{T} 7+\mathrm{S} 7$ with $\mathrm{T} 7$ extended ventrally to surround ligulate to linear (weakly sclerotized to membranous) remnant of S7; paired internal sclerites in genital chamber simplified and submembranous, situated more anteriorly than annular sclerite; annular sclerite widened, with thickened sides; spermathecae very small compared to ventral receptacle, suboval to pyriform, with transversely striated surface and at most slightly depressed apex; spermathecal ducts very long; ventral receptacle with characteristic dilated middle part and slender vermicular distal part with apex shortly twisted. At least some of these are unique apomorphies of this group, e.g. postgonite without seta or setula, distinctive construction of filum of distiphallus (with tuberculate surface) or characteristically formed ventral receptacle.

The phylogenetic relationships of $A$. flavosterna have been discussed several times in the past on the basis of morphological data (SUEYOSHI \& ROHÁČEK 2003; ROHÁČEK 2006, 2009; ROHÁČEK \& BARBER 2016), and, most recently, by means of molecular methods (ROHÁČEK et al. 2019) but the results have not been consistent. Even the hypotheses obtained by means of different methods of molecular analysis (ROHÁČEK et al. 2019) have not been in agreement as regards the phylogenetic position of $A$. flavosterna. The most recent morphological analysis has suggested its affinity to the $A$. bellatrix group (ROHÁČEK \& BARBER 2016: 381 and fig. 605) as did the molecular hypothesis obtained using a maximum likelihood method, although the support of this sister-group relationship was poor in the latter (RoHÁČEK et al. 2019: 753, fig. 2b). However, the two species recently described from China, viz. A. ornata Roháček, 2018 and A. sulphurea Roháček, 2018, could also be candidates for closer relationship not only with the $A$. bellatrix group (as suggested by RoHÁČEK 2018: 70 ) but also with the $A$. flavosterna group. To clarify this affinity, more representatives of the A flavosterna group, A. bellatrix group, and some of the above Chinese species must be obtained to expand the Anthomyza dataset for a new molecular data analysis.

\section{Anthomyza caesarea sp. nov. \\ (Figs 22-25, 28-47)}

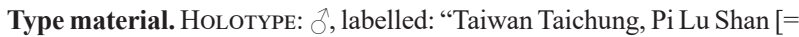
Bilushan], 24-25/VII/1990, W.C.Chuang, Sweeping net" and "Holotypus o', Anthomyza caesarea sp. n., J. Roháček det. 2019" (red label). The specimen is dry mounted on a minuten pin but somewhat damaged (Fig. 22), with left wing and some legs or its parts absent, abdomen cleared, with genitalia dissected and all parts preserved in glycerine in a pinned plastic tube together with left hind leg (NMNS). PARATYPES: $2+q$, with same label data as for the holotype, only second (type) label yellow with "Paratypus O"; both specimens somewhat damaged (Figs 23, 25), one (on minuten pin) without left wing and with right wing removed for photography and preserved in glycerine together with abdomen, the other (glued on a pinned triangular card) with wings stuck together basally, each specimen with abdomen detached, cleared and preserved in glycerine in a plastic tube pinned below (NMNS).

Description. Male. Large species, total body length $3.26 \mathrm{~mm}$; distinctly bicoloured, dorsally blackish brown, ventrally yellow (Fig. 22), very sparsely greyish microtomentose and hence rather shining, particularly dorsally.

Head slightly longer than high, with somewhat projecting frons and receding face, thus angular in profile (cf. Figs 22, 25). Occiput distinctly concave dorsomedially (cf. Fig. 23), dark brown dorsolaterally but with medial band above foramen pale brown to ochreous and completely ochreous to yellow below foramen. Frons largely dull yellow to (posteriorly) ochreous, only frontal (including darker ocellar) triangle and posterior part of orbit brown and shining despite some grey microtomentum. Orbits dull yellow and whitish microtomentose anteriorly (up to posterior ors), brown and more shiny posteriorly. Frontal triangle well delimited, narrow, reaching anterior third of frons. Frontal lunule small, depressed, yellow. Face narrow, medially concave and yellow, laterally pale brown; parafacialia and gena ochreous but silvery-white microtomentose, both bordered by relatively wide, pale-brown marginal stripe; postgena yellow like ventral part of occiput, somewhat whitish microtomentose and with posteroventral corner rounded rectangular; mouthparts ochreous. Cephalic chaetotaxy (cf. Figs 22, 25): pvt relatively long but thin, strongly crossed; vti and oc unusually long, by far the longest of cephalic setae but oc thinner than vti; vte about as long as posterior ors; 3 ors of moderate length, middle ors subequal to or slightly shorter than posterior ors, anterior 


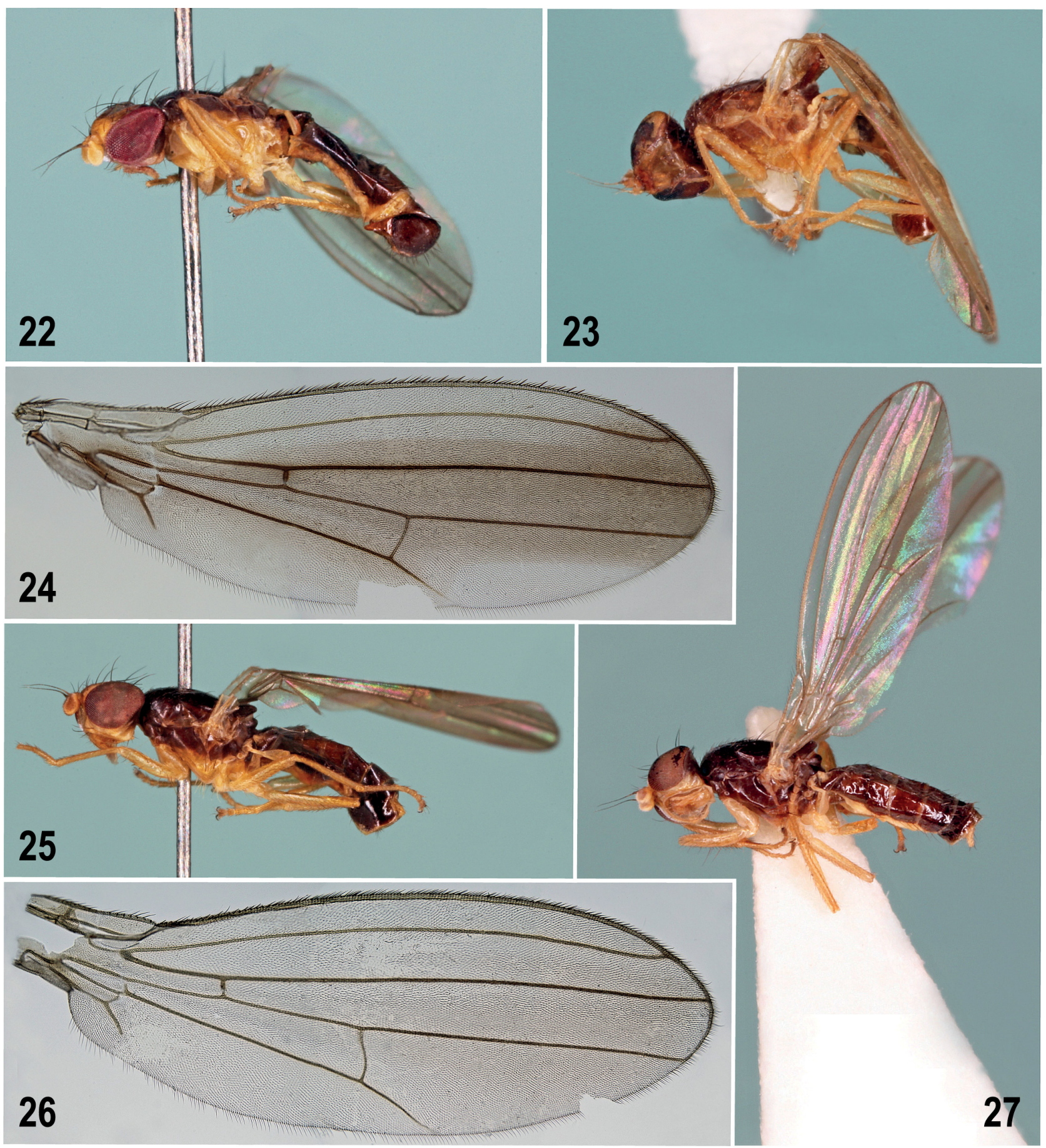

Figs 22-27. Anthomyza species from Taiwan. 22-25 - A. caesarea sp. nov., male and female: 22 - male holotype before dissection, laterally (body length ca. $3.3 \mathrm{~mm}$ ); 23 - female paratype before dissection, laterally (body length ca. $3.4 \mathrm{~mm}$ ); 24 - wing, female paratype (length ca. $3.9 \mathrm{~mm}$ ); 25 - female paratype before dissection, laterally (body length ca. $3.5 \mathrm{~mm}$ ); 26-27 - A. elongata sp. nov., female: 26 - wing, female paratype (length ca. $3.7 \mathrm{~mm}$ ); 27 - female holotype, laterally (body length ca. $3.4 \mathrm{~mm}$ ). Photos by J. Roháček.

ors distinctly shorter than others; no microsetula in front of anterior ors; medial microsetulae in anterior third of frons unusually long and numerous, in 6 irregular pairs; 1 or 2 setulae behind vte slightly longer than uppermost postocular; 7-8 relatively long postocular setulae, in single row; postgena with a few scattered setulae, also 2 or 3 relatively short posteroventral setae; 1 weak vi, shorter and finer than middle ors; subvibrissa about two-thirds length of vi and finer; 4 fine and sparse, relatively long peristomal setulae but slightly shorter than subvibrissa. Palpus small and slender, ochreous yellow, with 1 dark preapical seta and 3 or 4 paler ventral setulae. Eye ovoid (Fig. 22), with longest diameter oblique and about 1.5 times as long as the shortest. Shortest genal height about 0.1 times as long as shortest eye diameter. Antenna geniculate, entirely yellow; pedicel with relatively long exclinate dorsal seta; 1st flagellomere with white pilosity on anteroventral margin slightly longer than that of arista. Arista brown to pale brown (basal segment lighter brown) and 1.9 times as long as antenna, very shortly ciliate. 
Thorax as wide as head, dorsally brown to blackish, sparsely grey microtomentose and relatively shining, only narrow notopleural area yellow. Pleural part of thorax largely yellow but dorsally with broad longitudinal brown band extended from cervix to metanotum (cf. Figs 22, 25). Thoracic chaetotaxy (all macrosetae relatively thin): $1 \mathrm{hu}$ (as long as anterior npl); $2 \mathrm{npl}$ (anterior longer); 1 short weak prs; 1 subequally short sa; 1 long pa; 2 long postsutural dc (anterior shorter than posterior) and 5 or $6 \mathrm{dc}$ microsetae in front of them; 4 rather irregular rows of ac microsetae on suture, only 2 medial rows more posteriorly, almost reaching to level of posterior dc; $2 \mathrm{sc}$, laterobasal small and weak (shorter than prs), apical as long as posterior $\mathrm{dc} ; 1$ minute hair-like and pale ppl; 2 relatively strong and dark stpl, anterior only slightly shorter, and 1 pale setula in dorsal half of sternopleuron, its ventral part with a cluster of 5 or 6 longer yellow setae. Scutellum rounded triangular, distinctly convex dorsally. Subscutellum well developed and more densely grey microtomentose. Legs entirely pale yellow, including last tarsal segments. $\mathrm{f}_{1}$ (cf. Fig. 29) with short ctenidial spine, distinctly shorter than maximum width of $t_{1} ; f_{2}$ (Fig. 30 ) with a row of fine but erect posteroventral setae in proximal half; $f_{3}$ with long anteroventral row of setae, 7 of which (in distal third) thickened and shortened (Fig. 31); $\mathrm{t}_{2}$ with very short ventroapical seta (Fig. 30); $\mathrm{t}_{1}, \mathrm{t}_{3}$ and all tarsi simply setulose, only hind basitarsus with several ventrobasal setulae longer (Fig. 31) . Wing (cf. Fig. 24) very long, narrow, with pale ochreous or brown veins. Wing membrane with unusual broad, brown longitudinal band running in middle of wing across its whole length. $\mathrm{C}$ with distinct but sparse spinulae between apices of $R_{1}$ and $R_{2+3}$. $R_{2+3}$ very long, running parallel and close to $\mathrm{C}$ with apex upcurving; $\mathrm{R}_{4+5}$ very slightly bent, subparallel to $\mathrm{M}$ distally. Cell dm narrow, elongate, widened distally, with r-m situated in its proximal two-fifths. Apical portion of $\mathrm{CuA}_{1}$ distinctly longer than $\mathrm{dm}-\mathrm{cu}$ and reaching wing margin; $\mathrm{A}_{1}$ short, ending far from margin. Alula small, narrow. Wing measurements (holotype): length $3.22 \mathrm{~mm}$, width $0.93 \mathrm{~mm}, \mathrm{Cs}_{3}: \mathrm{Cs}_{4}=$ $1.27, \mathrm{rm} \backslash \mathrm{dm}-\mathrm{cu}: \mathrm{dm}-\mathrm{cu}=3.04$. Haltere yellow, with stem more or less darkened.

Abdomen elongate, slender. Preabdominal terga brown to blackish brown, with some greyish microtomentum, subshining to shining (laterally), distinctly setose. T1 only laterally fused with $\mathrm{T} 2$, somewhat narrower and shorter than T2; T2-T5 large, subequal in length, broad and reaching far onto ventral side of abdomen. Preabdominal sterna narrow, yellow to pale yellow, with sparse whitish microtomentum; S1 not observed (lost during preparation). S2-S5 more finely setose than adjacent terga. S2 about as long as wide, wider than S3; S3 and S4 somewhat longer than wide; S5 largest, wider than long, widened posteriorly and more densely setose than other sterna. Postabdomen (Fig. 28): T6 transverse, entirely membranous and unpigmented, bare. S6-S8 fused together but with fusion lines distinct; S6 and S7 strongly asymmetrical, situated on left side of postabdomen, both strikingly paler (ochreous) than S8 and with only anterior marginal stripe dark brown; S6 with 2 setae, S7 with 1 seta; S8 longer than S6+S7 and dark brown, larger on left side and setose in posterior half. Genitalia. Epandrium (Figs 28, 32) subspherical, slightly broader than high, relatively long, with relatively dense setosity including 2 pairs of longer setae; anal fissure very small and narrow, rounded subtriangular. Cercus very small and short, finely micropubescent, with fine and pale setae, apical seta longest. Medandrium high but narrow, slightly tapered dorsally, dorsolateral corners hardly projecting. Gonostylus (Figs 28, 32, 36) relatively long (about 0.75 times epandrial height) but slender and only proximally broad, strongly tapered distally to acute apex, slightly incurved in caudal view (Fig. 32), ochreous yellow in contrast to dark-brown epandrium, almost lacking micropubescence, with only a few setulae on outer side but densely setose on inner side. Hypandrium (Figs $33,35)$ rather robust and compact, anterior internal lobes low, not projecting dorsally. Transandrium (Fig. 34) rather simple, dorsally with dark transverse ledge, medially with distinct caudal process being narrowed and pale-pigmented ventrally where coalesced with basal membrane. Pregonite (Figs 33, 35) completely fused to hypandrium, its anterior part slightly protruding ventrally and bent medially (as in $A$. flavosterna), anteromedially with 3 or 4 setae, posteriorly with a group of 3 or 4 closely clustered setae. Postgonite (Figs 33, 35) slender, longer than in A. flavosterna, apically blunt and with several sensilla but without any seta (also absent in A. flavosterna). Basal membrane bulging (Fig. 35), larger than in A. flavosterna, densely overgrown by numerous short and dense hyaline spines (Fig. 34). Aedeagal part of folding apparatus without spines or tubercles, only finely striated (Fig. 38). Connecting sclerite relatively large and long but partly unpigmented and weakly sclerotized (Fig. 38). Phallapodeme with very slender basal half and with basal end relatively symmetrically forked (Fig. 37), apically very shortly bicuspidate (Fig. 38). Aedeagus with phallophore simple but elongate (Fig. 38), of similar construction to that of A. flavosterna. Distiphallus large, bifid from near its base. Saccus relatively short, vesiculate, largely membranous, covered by dense, short and broad but hyaline spines (Fig. 38). Filum very robust and broad along most of its length (Fig. 38), with only base narrower, preapically curved and projecting as single elongate, sinuate process that is apically curved, hook-like (see Fig. 39); most of its surface covered by small tubercles (Fig. 38). Ejacapodeme very small, with short projection (Fig. 38).

Female. Similar to male unless mentioned otherwise. Total body length 3.40-3.46 mm. Frontal triangle (Fig. 23) pale ochreous, often lighter than adjacent parts of frons but ocellar triangle dark brown (as in male). Face, parafacialia, gena and postgena yellow and marginal stripe of parafacialia and gena paler. Antenna darker, orange (Fig. 25). Eye less elongate, its longest diameter 1.38-1.44 times as long as shortest. Ctenidial spine on $f_{1}$ (Fig. 29) small as in male. Both $\mathrm{f}_{2}$ and $\mathrm{f}_{3}$ posteroventrally simply setulose. Wing with $\mathrm{r}-\mathrm{m}$ situated at midlength of $\mathrm{dm}$ cell (Fig. 24). Wing measurements: length $3.49-3.98 \mathrm{~mm}$, width 0.99-1.05 mm, Cs $: \mathrm{Cs}_{4}=1.17-1.38, \mathrm{rm} \backslash \mathrm{dm}-\mathrm{cu}: \mathrm{dm}-\mathrm{cu}$ $=2.87-3.38$. Abdomen with $\mathrm{T} 2-\mathrm{T} 5$ subequal in length but shorter and distinctly more transverse than in male, all 
dark brown but lighter (Fig. 25) than postabdominal T6 and T7. Preabdominal sterna pale yellow and becoming slightly wider posteriorly. S2 shortest, S2 and S3 narrower than long, S4 and S5 about as long as broad, S5 largest and (posteriorly) widest.

Postabdomen (Figs 40-42) relatively long, gradually tapered posteriorly, with the narrow, weakly sclerotized and pale-pigmented end (from 8th segment) withdrawn at rest into large 7th segment (see Fig. 25). T6 broad (Fig. 41), almost as wide as T5 but only about half its length, somewhat lighter than $\mathrm{T} 7+\mathrm{S} 7$, densely setose. S6 very small (Fig. 42), narrower than S5, pale yellow, with relatively long but thin setae in posterior half. Tergosternum T7+S7 (Figs 40-42) prolonged, tapered posteriorly and characteristically formed, with tergal part enlarged and setose, and sternal part extremely reduced (narrowed); largely blackish brown but dorsally with large, irregular posteromedial pale-brown area (Fig. 41); extended laterally far onto ventral side (Fig. 42) leaving only a very narrow, medial membranous sternal strip (= remnant of S7) bearing single pair of setae. T8 elongate and narrow (narrower than in A. flavosterna), pale-pigmented, with fine transverse
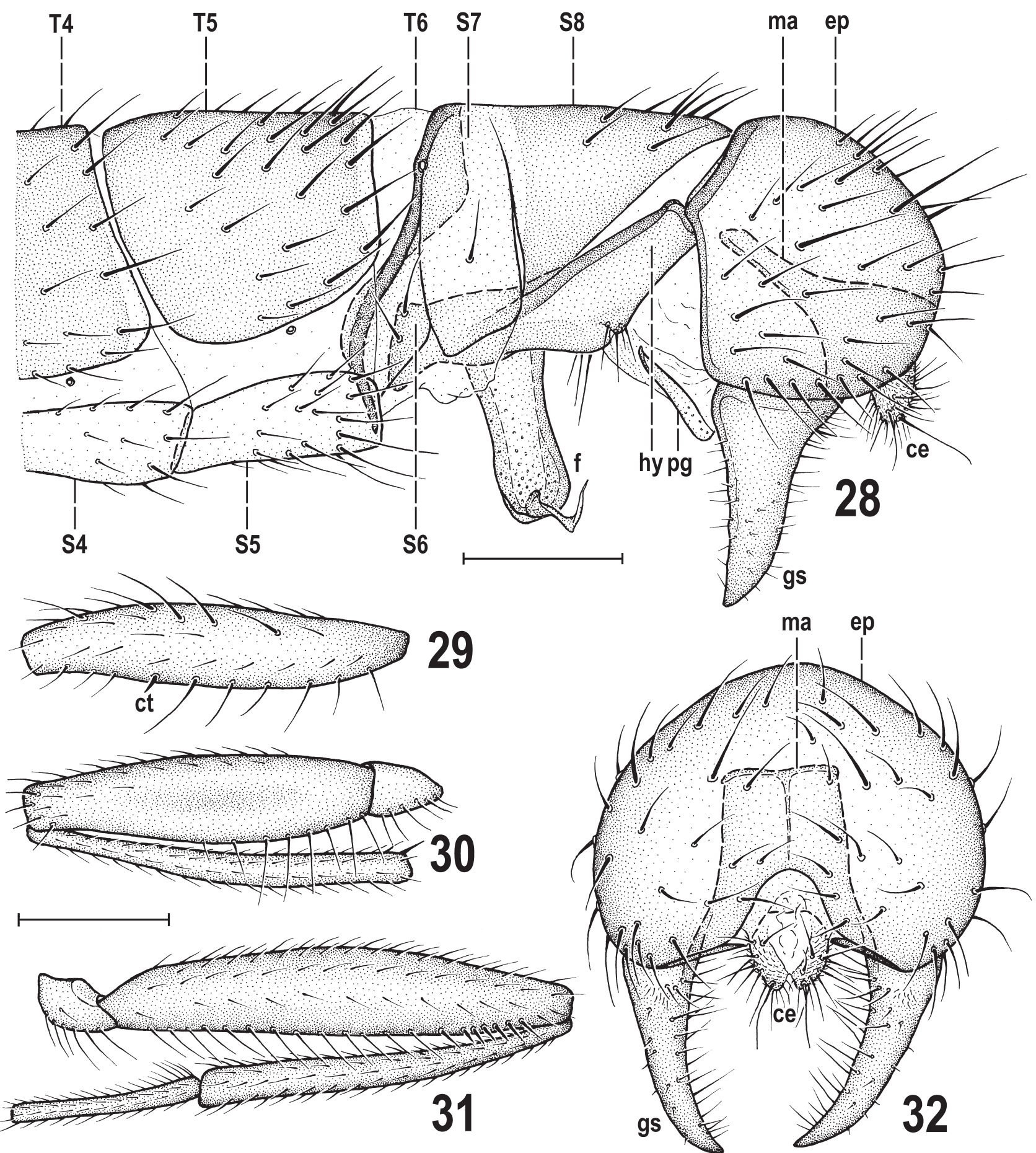

Figs 28-32. Anthomyza caesarea sp. nov., male holotype, female paratype. 28 - end of male abdomen in situ, laterally; 29 - female $\mathrm{f}_{1}$, posteriorly; 30 male trochanter, $\mathrm{f}_{2}$ and $\mathrm{t}_{2}$, posteriorly; 31 - male trochanter, $\mathrm{f}_{3}, \mathrm{t}_{3}$ and hind basitarsus, anteriorly; $32-$ male external genitalia, caudally. Scales $=0.2$ mm (Figs 28, 32), $0.3 \mathrm{~mm}$ (others). For abbreviations see pp. 270-271. 
microsculpture (Fig. 41) and fine posterior and posterolateral setae; S8 much shorter than T8, narrowly divided medially into 2 pale-pigmented sclerites (Fig. 42). Genital chamber with reduced internal sclerotization (Fig. 46, is): consisting of a single pair of submembranous, poorly delimited sclerites situated anterior to a well-sclerotized and curved annular sclerite with widened sides (Fig. 47).
Ventral receptacle (Figs 45, 46) long, tube-like, with basal duct hyaline, middle part broad and darkened, and apex vermicularly twisted but relatively short; remnant of accessory gland small, granulose (Fig. 46), on slender duct having its widest part somewhat ringed. Spermathecae $(1+1)$ on extremely long ducts, pyriform, one distinctly larger than the other (Figs 43, 44), each with slightly de-
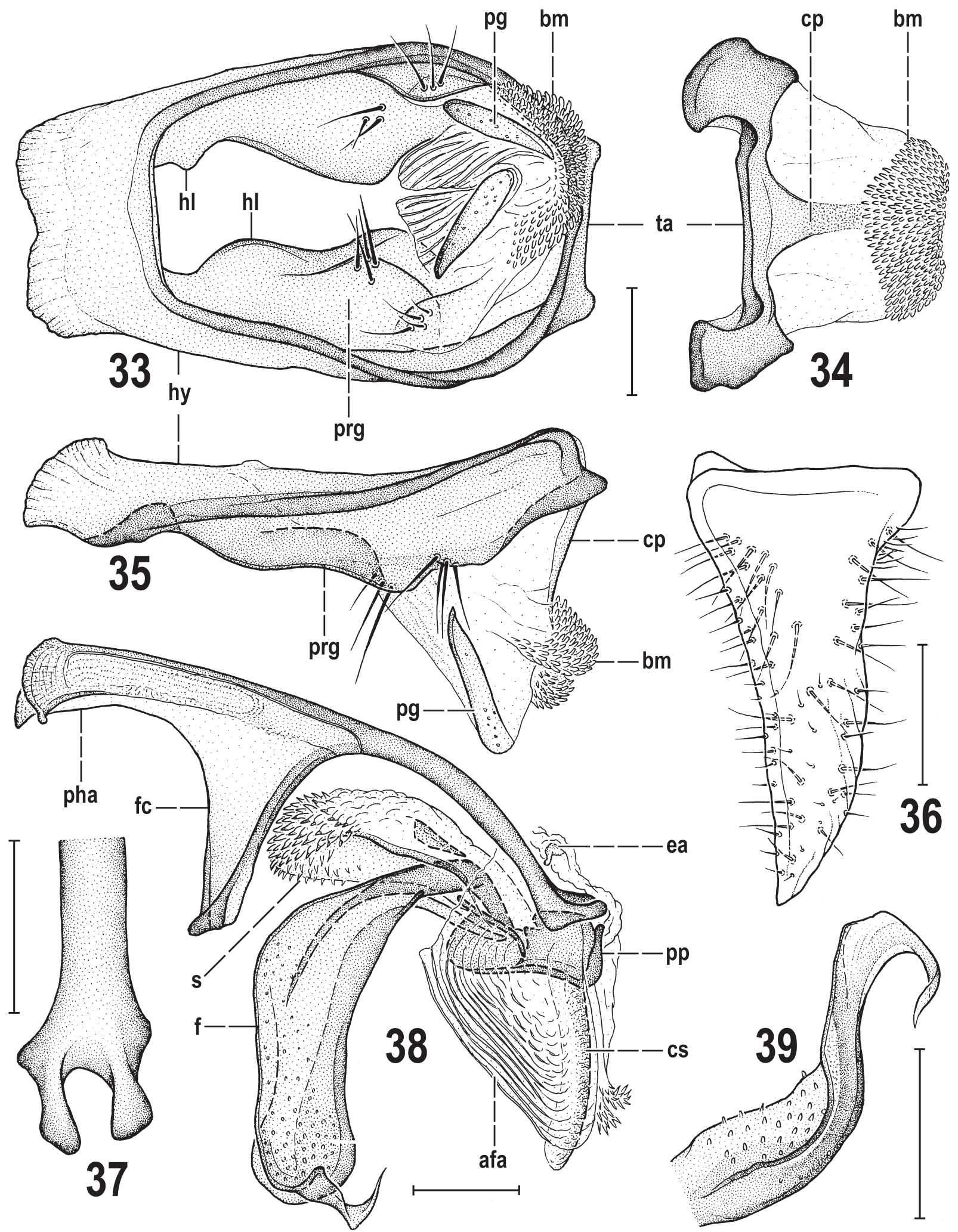

Figs 33-39. Anthomyza caesarea sp. nov., male holotype. 33 - hypandrium, ventrally; 34 - transandrium, caudally; 35 - hypandrium, laterally; 36 gonostylus, lateroventrally (widest extension); 37 - base of phallapodeme, dorsally; 38 - aedeagal complex, laterally; 39 - apex of filum of distiphallus, ventrally. All scales $=0.1 \mathrm{~mm}$. For abbreviations see p. pp. 270-271. 
pressed apex, transversely striated surface in distal half, small tuberculiform spinulae on basal half, and small brownish cervix. T10 small but elongately shield-shaped (Fig. 41), very pale, with single medial pair of relatively short setae and reduced micropubescence. S10 broader and longer than T10, elongately rounded pentagonal (Fig. 42), with very dense fine micropubescence and fine marginal setae. Cercus (Figs 40, 41) long and slender (in contrast to that of A. flavosterna), pale-pigmented, with apical and dorsopreapical setae longest but both shorter than cercus. Discussion. Anthomyza caesarea sp. nov. so closely resembles the species of the genus Epischnomyia Roháček, 2006 in body and wing colouration that it had originally been considered a member of this East Asian genus. However,

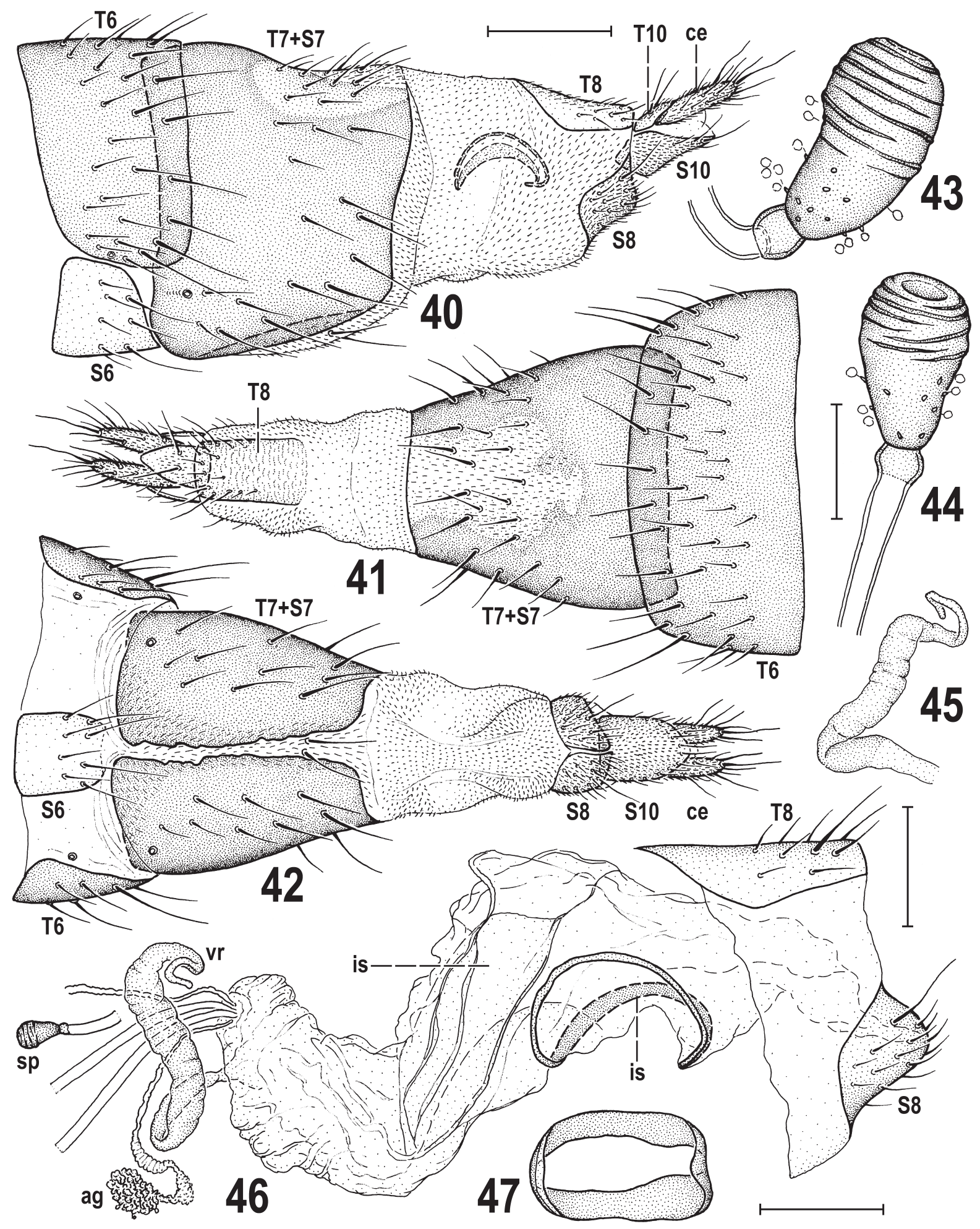

Figs 40-47. Anthomyza caesarea sp. nov., female paratype. 40 - postabdomen, laterally; 41 - the same, dorsally; 42 - the same, ventrally; $43-44$ spermathecae; 45 - ventral receptacle, subventrally; 46 - genital chamber with 8 th abdominal segment, laterally; 47 - annular sclerite, ventrally. Scales $=0.2 \mathrm{~mm}$ (Figs 40-42), $0.03 \mathrm{~mm}$ (Figs 43, 44) and 0.1 mm (others). For abbreviations see pp. 270-271. 
the examination of the male and female terminalia revealed this large Anthomyza species with distinctly longitudinally banded wings (Fig. 24) is related to A. flavosterna. Four additional species allied to the latter species have been discovered in Taiwan, which are now placed in the separate A. flavosterna group (see above). However, A. caesarea sp. nov. is the most aberrant of these relatives differing from all of them, not only by the patterned wings but also by the most derived characters of the male terminalia (reduced cerci and anal fissure, narrow and acute gonostylus, large and broad filum of distiphallus, no sclerotized armature of aedeagal part of folding apparatus) and female postabdomen (very small S6, large and strongly modified T7+S7 with $\mathrm{S} 7$ reduced to a membranous medial strip, elongated and pale-pigmented 8th +10 th abdominal segments). Based on some shared apomorphic characters, this new species seems to be the nearest ally of $A$. elongata sp. nov. (for their synapomorphies, see discussion under the latter species).

Etymology. This new species is named to reflect its large, unusally bicoloured body and longitudinally brown-patterned wings (caesareus $=$ imperial, Latin adjective).

Biology. Unknown. The type specimens (1 male 2 females) were swept from vegetation in June in a montane location (about 2400-2500 m).

Distribution. Taiwan: Taichung City area.

\section{Anthomyza elongata sp. nov.} (Figs 26, 27, 48-55)

Type material. HoLOTYPE: + , labelled: "TAIWAN, Ali-shan [= Alishan], 2584 m, Oct. 31, 1985, K. Kanmiya" and "Holotypus $\odot$, Anthomyza elongata sp. n., J. Roháček det. 2019" (red label). The specimen is intact (Fig. 27), dry mounted on a pinned triangular card (SMOC). PARATYPES: 2 우 , with same label data as for the holotype, only second (type) label is yellow with "Paratypus". Abdomen of each female cleared, dissected and preserved in glycerine in a pinned plastic tube, in one of them together with one wing (used for photography) (SMOC).

Description. Male unknown.

Female. Large species, total body length 3.25-3.41 mm; general colour blackish brown (thorax) to brown (abdomen), very sparsely greyish microtomentose and hence distinctly shining (Fig. 27). Only anterior and ventral parts of head, ventral corner of sternopleuron and abdominal sterna yellow or ochreous.

Head as long as high, with slightly projecting frons and receding face, thus somewhat angular in profile. Occiput dorsomedially concave, blackish brown but ventrally (below foramen) yellow; occiput sparsely darkgrey microtomentose, only the medial stripe running from ocellar triangle to foramen bare and shining. Frons dark brown, only anterior fourth to third yellow, largely microtomentose. Frontal (including ocellar) triangle and orbits silvery-grey microtomentose and somewhat glittering, contrasting with dull blackish-brown stripes between them meeting in front of anterior corner of frontal triangle. Orbit yellow only anteriorly (up to middle ors), brown between middle and posterior ors, dark brown and more shiny posterior to the latter. Frontal triangle relatively broad, reaching only to anterior two-fifths of frons. Frontal lunule small, narrow and depressed, yellow.
Face narrow, medially concave, light yellow with whitish microtomentum; parafacialia and gena yellowish white and silvery-white microtomentose, both bordered by relatively wide, ochreous-yellow marginal stripe; postgena largely pale yellow and whitish microtomentose, concolourous with ventral part of occiput; mouthparts dark yellow to ochreous. Cephalic chaetotaxy: pvt of moderate length, thin and crossed; vti very long, by far the longest of cephalic setae; vte shorter than oc; 3 moderately long but relatively thin ors, becoming shorter anteriorly, posterior ors as long as vte; middle ors arising closer to anterior ors than to posterior ors; no microsetula in front of the anterior ors; 2-4 pairs of relatively long, medial microsetulae in the yellow anterior part of frons; 1 or 2 setula(e) behind vte slightly longer than dorsal postoculars; the latter sparse (5 or 6 ), in single row but occiput with several additional scattered setulae; postgena with a few small setulae, also 2 short and weak posteroventral setae; 1 relatively weak vi, about as long as middle ors but finer; subvibrissa reduced, less than half length of vi and only slightly longer than fine and sparse (3 or 4) peristomal setulae. Palpus elongate, slender, yellow, with 1 distinct black preapical seta and 3 or 4 shorter, dark ventral setulae. Eye broadly ovoid (in contrast to most of relatives), with longest diameter oblique and only about 1.3 times as long as the shortest. Shortest genal height about 0.17 times as long as shortest eye diameter. Antenna geniculate, yellow to orange; 1st flagellomere with very short, white pilosity on anteroventral margin (about as long as that of arista). Arista with pale-brown basal segments and blackish terminal part, 1.9-2.0 times as long as antenna, very shortly ciliate.

Thorax slightly narrower than head, blackish brown dorsally to brown laterally, very sparsely grey microtomentose and shining (its pleural part subshining); only sternopleuron (Fig. 27) gradually lightened from brown dorsally to yellow ventrally (sometimes with only ventral corner yellow); hypopleuron also often paler brown, particularly ventrally. Thoracic chaetotaxy (all macrosetae relatively thin, most dark but some thinner ones pale-pigmented): $1 \mathrm{hu}$, as long as posterior npl; $2 \mathrm{npl}$ (anterior markedly longer); 1 weak prs, shorter and finer than hu; 1 weak sa (as long as prs); 1 longer pa; 2 postsutural dc, anterior thinner and about two-thirds length of posterior dc (longest thoracic seta); 6-8 dc microsetae in front of anterior dc; 4 irregular and incomplete rows of ac microsetae on suture, only 2 medial rows more posteriorly (between $\mathrm{dc}$ ), not reaching to level of posterior $\mathrm{dc} ; 2 \mathrm{sc}$, laterobasal small and weak (shorter than prs), apical almost as long as posterior dc; 1 minute, upcurved and pale ppl; 2 dark stpl, posterior long, anterior about two-thirds of posterior and thinner; no setulae in dorsal half of sternopleuron; its ventral, yellow corner with 4 longer yellow setae. Scutellum rounded triangular, very slightly convex to flat dorsally. Legs yellow, with coxae whitish yellow, only last tarsal segments or their distal half brownish (Fig. 27). $f_{1}$ with very short ctenidial spine, no more than half maximum width of $t_{1}$ and with long fine setae in posteroventral and posterodorsal rows; $t_{2}$ with short ventroapical seta, only slightly longer than distal 


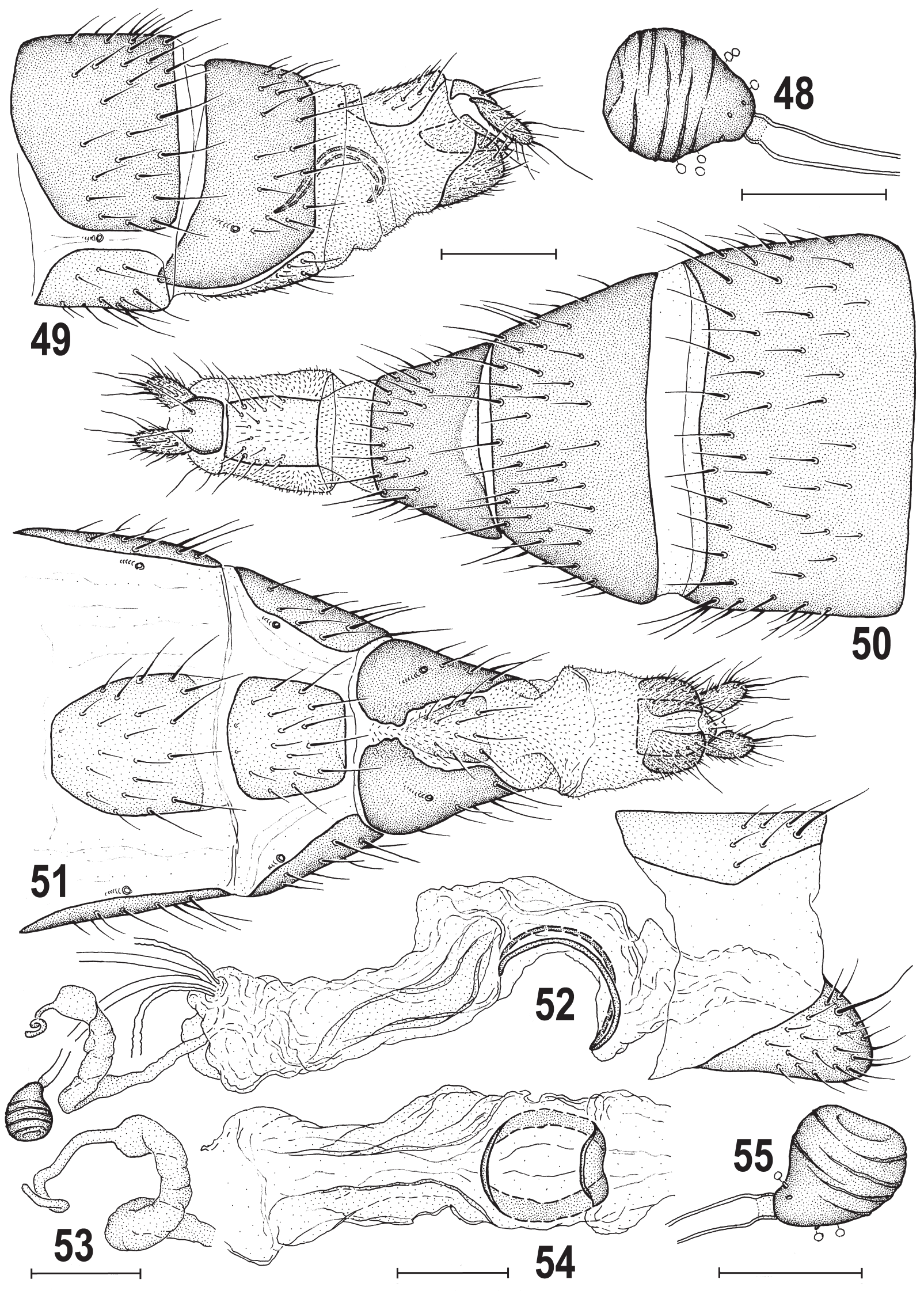

Figs 48-55. Anthomyza elongata sp. nov., female paratype. 48 - spermatheca; 49 - postabdomen, laterally; 50 - postabdomen with 5th abdominal segment, dorsally; 51 - the same, ventrally; 52 - genital chamber with 8th abdominal segment, laterally; 53 - ventral receptacle, subventrally; 54 - internal sclerites, ventrally; 55 - spermatheca. Scales $=0.2 \mathrm{~mm}$ (Figs 49-51), $0.03 \mathrm{~mm}$ (Figs 48, 55), $0.05 \mathrm{~mm}$ (Fig. 53 ) and $0.1 \mathrm{~mm}$ (others). 
width of $\mathrm{t}_{2} ; \mathrm{f}_{2}, \mathrm{f}_{3}, \mathrm{t}_{1}, \mathrm{t}_{3}$ and all tarsi simply setulose, only hind basistarsus with a few ventrobasal setulae longer. Wing (Fig. 26) very long, relatively narrow, with pale ochreous veins and membrane. $\mathrm{C}$ with sparse spinulae between apices of $R_{1}$ and $R_{2+3}$. $R_{2+3}$ very long, running parallel to $\mathrm{C}$, with apex slightly upcurving; $\mathrm{R}_{4+5}$ very slightly bent, more or less parallel to $\mathrm{M}$ apically. Cell $\mathrm{dm}$ long and very narrow, distally widened, with $\mathrm{r}-\mathrm{m}$ situated in its proximal two-fifths. Apical portion of $\mathrm{CuA}_{1}$ distinctly longer than $\mathrm{dm}-\mathrm{cu}$ and almost reaching wing margin; $\mathrm{A}_{1}$ short, ending far from margin. Alula small, narrow. Wing measurements: length 3.89-4.09 mm, width 1.15-1.21 mm, $\mathrm{Cs}_{3}: \mathrm{Cs}_{4}=$ 0.95-1.21, rm \dm-cu : dm-cu $=2.79-3.34$. Haltere yellow to ochreous, with knob slightly darker.

Abdomen. Preabdominal terga brown to dark brown (darker laterally), relatively densely setose, with sparse greyish microtomentum and relatively shining (Fig. 27) but slightly less so than mesonotum. T1 only laterally fused with T2, distinctly narrower and shorter than T2; T2-T5 large, transverse, reaching onto ventral side of abdomen, subequal in length. T3 and T4 slightly wider than T2 and T5. Preabdominal sterna ochreous to pale brown, very narrow; S1 shortest, transverse and bare, S2-S5 with sparse, fine setae; S2 darkest and with brown anterior marginal stripe; S2-S4 distinctly longer than wide; S3 slightly narrower than S2 or S4; S5 only slightly longer than wide, wider than S4, with unpigmented posterior margin (Fig. 51).

Postabdomen (Figs 49-51) elongately conical, more tapered laterally (Fig. 50) than dorsoventrally (Fig. 49). T6 large, almost as wide as T5 anteriorly but strongly tapered posteriorly (Fig. 50), entirely blackish brown, with relatively dense but fine setae. S6 relatively narrow (but larger than that of $A$. caesarea), about as long as wide (Fig. 51), somewhat narrower posteriorly, ochreous, with a number of fine long setae. Tergosternum $\mathrm{T} 7+\mathrm{S} 7$ dorsally shorter (shortest dorsomedially) and blackish brown except for small anteromedial pale-pigmented area (Fig. 50); ventrally longer and its dark anteroventral parts extended to almost meet medially (Fig 51), posteromedially with pale-brown, more or less distinctly delimited, narrowly subtriangular area (= remnant of S7) being setose in posterior two-thirds and distinctly micropubescent anteriorly (Fig. 51). T8 elongate, narrow, semicylindrical and pale-pigmented as in A. flavosterna, with fine setae at posterior and lateral margins; S8 shorter than T8, broadly divided medially into two convex to bulging, pale-brown and shortly setose sclerites (see Figs 51, 52). Genital chamber with reduced internal sclerotization (Figs 52, 54) as in A. caesarea, with single pair of sclerites longer but also submembranous and poorly delimited, situated anterior to the annular sclerite; annular sclerite well developed and similar to that of $A$. caesarea but broader in ventral view (Fig. 54). Ventral receptacle (Figs 52, 53) also resembling that of $A$. caesarea, having basal part narrower and hyaline, middle part wider and darkened, but the latter terminally smooth, pale and projecting in longer vermicular terminal part with apex shortly twisted (Fig. 53); remnants of accessory gland not seen, probably small, on simple slender duct. Spermathecae (1+1) most similar to those of $A$. caesarea but short pyri- form (Figs 48, 55), with a few, and less distinct, transverse striae and reduced (both in number and size) tuberculiform spinulae; cervix smaller and paler. T10 small (Fig. 50) but longer and less transverse than that of A. flavosterna, with usual medial pair of longer setae, lacking micropubescence. S10 (Fig. 51, retracted) only slightly wider but distinctly longer than T10, elongately rounded pentagonal, with fine micropubescence and marginal setae. Cercus relatively short and robust (Figs 49, 50), most similar to that of $A$. flavosterna but pale-pigmented and its setae finer.

Discussion. Anthomyza elongata sp. nov. is another member of the Anthomyza flavosterna group. It resembles the above species, $A$. caesarea sp. nov. and also $A$. sp. nov. near elongata by its large size but differs from both these species by its blackish-brown thorax, including its pleural part with only the ventral corner of the sternopleuron yellow. In the latter character, it resembles the much smaller A. flavosterna but differs from the latter in having a broad frontal triangle, a broadly ovoid eye and the last tarsal segments brownish. It is also recognizable by the form of structures of the female postabdomen, many of which are intermediate between those of $A$. flavosterna and $A$. caesarea sp. nov.: the tergosternum $\mathrm{T} 7+\mathrm{S} 7$ with a distinct remnant of $\mathrm{S} 7$, short T10 and short robust cerci resemble more those of A. flavosterna, while the narrow S6, submembranous paired sclerites and shape of the annular sclerite in the genital chamber, and pyriform spermathecae are more similar to those of $A$. caesarea sp. nov. However, the detailed construction of all the above-discussed structures is more or less different (see description) from those of these two species. Considering the formation of the postabdominal sclerites, A. elongata sp. nov. seems to be closest to an unnamed species diagnosed below, viz. $A$. sp. nov. near elongata. The differences between these two species are enumerated below in the diagnosis of the latter species. The long and posteriorly tapered 6th segment (including T6, Fig. 50) seems to be unique to A. elongata sp. nov.

Etymology. This species is named for its long and slender body and wings (elongatus = elongate, Latin adjective).

Biology. Anthomyza elongata is known only from 3 females collected in October in the Alishan mountain range at $2584 \mathrm{~m}$ a. s. 1.

Distribution. Taiwan: Chiayi County.

\section{Anthomyza sp. nov. near elongata}

Material examined. TAIWAN: Ilan [= Yilan County]: Tatung Chilanshan [= Qilanshan], sweeping net, 15.ix.1992, 1 +, W. T. Yang leg. (NMNS, damaged, genit. prep.).

Diagnosis. Large species (body length $3.53 \mathrm{~mm}$, wing length $3.85 \mathrm{~mm}$, wing width $1.15 \mathrm{~mm}$ ) closely resembling A. elongata sp. nov. but differing as follows: eye slightly more oval; frons with anterior half yellow; frontal triangle broad but short (reaching only to about middle of frons) and dull brown (markedly paler than in A. elongata); stripes between frontal triangle and orbits also dull brown and short, not reaching in front of frontal triangle; sternopleuron almost entirely yellow with only anterodorsal corner pale brown; hypopleuron ochreous to pale brown. Postabdomen also similar to that of $A$. elongata but T6 
shorter and not tapered posteriorly; S6 broad, distinctly wider than long; $\mathrm{T} 7+\mathrm{S} 7$ longer, with anteroventral corners of its original T7 pale brown, extended onto ventral side and meeting medially; remnant of S7 forming membranous, almost unpigmented triangle behind these corners but long setose (as is $\mathrm{S} 7$ of $A$. elongata); S8 longer and with longer setae; ventral receptacle with middle dilated part hyaline and vermicular distal part with apex more (twice) twisted; spermathecae most similar to those of $A$. elongata, shortly pyriform; cercus relatively long but wider than in A. elongata.

Discussion. This undescribed species is left unnamed because there is only a single, somewhat damaged female available for examination. It is a member of the A. flavosterna group (as defined above) and undoubtedly the closest relative of another Taiwanese species, A. elongata sp. nov. (see diagnosis above). It will be described as and when additional material (including males) is obtained for study. Biology. Unknown. The only known female was swept from vegetation in September.

Distribution. Taiwan: Yilan County.

\section{Anthomyza sp. nov. (1) near flavosterna}

Material examined. TAIWAN: Chiayi [County]: Alishan, sweeping net, 4.x.1988, 3 ô, K. S. Huang leg. (NMNS, all heavily damaged, 1 genit. prep., $1 \hat{\delta}$ headless).

Diagnosis. Smaller, slender species (body length ca. 2.7 $\mathrm{mm}$, the only measurable wing length $2.65 \mathrm{~mm}$, wing width $0.85 \mathrm{~mm}$ ) similar to A. flavosterna but differing as follows: thorax (including ventral part of pleuron) and abdomen dorsally blackish brown and shining; frons ochreous orange to yellow in anterior half; frontal triangle moderately long and broad (reaching to anterior third of frons), brown but relatively shiny due to sparse microtomentum; stripes between frontal triangle and orbits dull brown, only anteriorly paler; entire sternopleuron blackish brown; legs dark yellow but 2 or (sometimes) 3 terminal segments of tarsi brown; dorsal abdominal sclerites lustrous, almost lacking micropubescence. Male genitalia similar to those of $A$. flavosterna but gonostylus more oblong (with less convex anterior margin); phallapodeme with apex distinctly dilated laterally; pregonite with 6 setae in posterior group; saccus smaller and narrower; filum of distiphallus similar but basally twice broader, lacking the acute corner distally and its terminal slender projection distinctly longer and twisted in front of sharply acute apex.

Discussion. This is another distinctive new species which cannot be named and described because all studied specimens are heavily damaged including tattered wings, broken legs, antennae and setae. It is recognized as a close relative of $A$. flavosterna, particularly because of the very similarly formed male genital structures, including the pregonite, phallapodeme and distiphallus but for differences see above diagnosis. Formal description of this unusually dark and shining species requires additional and better-preserved material.

Biology. Unknown. The three males examined were swept in October in the Alishan mountain range.

Distribution. Taiwan: Chiayi County.

\section{Anthomyza sp. nov. (2) near flavosterna}

Material examined. TAIWAN: Nantou [County]: Hsini Patungkuan [=Batongguan, Xinyi Township], sweeping, 13.-15.vi.1989, $2 \lesssim 2$ 우, K. W. Huang leg. (NMNS, all heavily damaged, $101+$ genit. prep., 1 q with wings lost).

Diagnosis. Small species (body length ca. 2.2-2.4 mm, wings not measurable) differing from all relatives by lighter body colouration. It most closely resembles $A$. flavosterna but differs from it as follows: head largely yellow; thorax with brown (not dark-brown) mesonotum; pleural part of thorax only dorsally pale brown, ventrally yellow; also abdomen dorsally pale brown; head yellow to pale yellow including most of frons, only occiput (above foramen) brown and frontal triangle pale brown; frontal triangle short and broad (reaching middle of frons); thorax sparsely light-grey microtomentose, subshiny; pleuron yellow ventrally (including sternopleuron and hypopleuron) but also ventral part of propleuron and mesopleuron ochreous, rest of pleuron pale brown. Male genitalia most closely resembling those of $A$. flavosterna but gonostylus with both anterior (proximally) and posterior (more distally) margins convex, distinctly tapered towards the apex which is subacute and ending in 2 denticles; anterodorsal third of gonostylus lacking micropubescence; posterior part of postgonite less projecting and with only 2 setae; filum of distiphallus wider proximally and less dilated distally but terminally similar to that of A. flavosterna in having an acute (but more slender) tooth and the usual, long, slender, sinuously curved and apically pointed projection. Female postabdomen also most similar to that of A. flavosterna but differing as follows: all sclerites distinctly paler; $\mathrm{T} 7+\mathrm{S} 7$ longer and its tergal part brown (darkest abdominal sclerite); original S7 membranous and unpigmented, distinctly wider and almost parallel-sided (not tapered anteriorly); spermathecae longer, elongately pyriform (as in A. caesarea) but relatively large, with more densely transversely striated surface in the wider distal half and with well-developed, dark-pigmented cervix. Ventral receptacle similar to that of A. flavosterna but with the dilated hyaline middle part distinctly longer, the narrowed distal part also longer with apex simply twisted. Cercus similarly shaped to that of A.flavosterna but pale-pigmented.

Discussion. This new species also remains unnamed and undescribed because the specimens are very damaged. It seems to be most closely allied to A. flavosterna (more closely than is $A$. sp. nov. (1) near flavosterna treated above) judging from the formation of the terminal part of the filum of the distiphallus (having an acute tooth in addition to a long projection) in the male genitalia and the construction of the ventral receptacle in the female terminalia. However, it can be easily distinguished from A. flavosterna and all other relatives by the strikingly pale colouring of the head, thorax and abdomen. This species will be described in full when additional, well-preserved material becomes available.

Biology. Unknown. The four known specimens were swept in June.

Distribution. Taiwan: Nantou County. 


\section{A preliminary key to identification}

of the Taiwanese species of Anthomyza

(also includes A. flavosterna to cover the entire A. flavosterna group)

1 Head distinctly angular in profile (Figs 22, 25); occiput without whitish grey microtomentose stripes; 3 relatively weak ors becoming shorter anteriorly. Thorax sparsely grey microtomentose and relatively shining; sternopleuron more or less (at least its ventral corner) yellow (Figs 22, 25, 27); male $\mathrm{f}_{2}$ with posteroventral row of fine erect setae (Fig. 30); pregonite low, projecting little ventrally (Fig. 35); postgonite without seta or setula (Fig. 35); base of slender phallapodeme symmetrical (Figs 37, 38); phallophore elongate; filum robust and expanded distally, with finely tuberculate surface and slender, characteristically projecting apex (Figs 38, 39). Female T7+S7 long, with T7 extended ventrally to surround ligulate to linear (weakly sclerotized to membranous) remnant of S7 (Figs 42, 51); paired internal sclerites in genital chamber simplified and submembranous, situated more anteriorly than annular sclerite; annular sclerite widened, with thickened sides (Figs 46, 47, 52, 54).................................. 2 Head rounded in profile (Fig. 4); occiput with a pair of whitish grey microtomentose stripes; 2 long ors and 1 microsetula in front of anterior ors. Thorax densely grey microtomentose and dull; sternopleuron unicolourous, dark brown (Figs 4, 5); male $\mathrm{f}_{2}$ without posteroventral row of fine erect setae; pregonite with 2 lobes projecting ventrally (Fig. 11); postgonite with small seta (Fig. 11); base of robust phallapodeme strongly asymmetrical (Fig. 14); phallophore short, with ventral claw-like sclerite (Fig. 14); filum huge, formed by complex sclerite having surface plain and terminating in 2 long projections (Figs 13, 14). Female T7+S7 short, with sclerites T7 and S7 fused to form ring-shaped tergosternum (Figs 15-17); paired internal sclerites in genital chamber complex and asymmetrical, heavily sclerotized, situated posterodorsally to annular sclerite; annular sclerite slender and elongate (Figs 19, 21).

A. robusta sp. nov.

2(1) Large species, body and wing length more than 3.2 $\mathrm{mm}$.

- $\quad$ Smaller species, body and wing length less than 2.8 $\mathrm{mm}$.

3(2) Wing with longitudinal brown pattern (Fig. 24) Pleural part of thorax largely yellow with broad longitudinal brown band dorsally (Figs 22, 25). Gonostylus strongly tapered towards acute apex (Figs $28,36)$. Female $\mathrm{T} 7+\mathrm{S} 7$ with large posteromedial pale-brown area dorsally (Fig. 41), original S7 reduced to very narrow membranous strip with single pair of setae (Fig. 42). A. caesarea sp. nov. Wing unicolourous (Fig. 26). Pleural part of thorax largely dark brown, only sternopleuron or its ventral corner yellow. Male unknown. Female T7+S7 uniformly blackish brown dorsally, original S7 larger (although membranous), subtriangular and more setose (Fig. 51). ......................................................... 4

4(3) Frons with only anterior fourth to third yellow; frontal triangle and orbits silvery-grey microtomentose and somewhat glittering, contrasting with dull blackish-brown stripes between them which meet in front of anterior corner of frontal triangle; sternopleuron brown dorsally, yellow ventrally (Fig. 27). T6 large, almost as wide as T5 anteriorly but strongly tapered posteriorly (Fig. 50); S6 about as long as wide, somewhat narrowed posteriorly (Fig. 51). Male unknown. A. elongata sp. nov.

- Frons with anterior half yellow; frontal triangle dull brown, not contrasting with similarly coloured and adjacent microtomentose stripes which do not reach in front of frontal triangle; sternopleuron almost entirely yellow. T6 shorter and not tapered posteriorly; S6 broad, distinctly wider than long. Male unknown.

A. sp. nov. near elongata

5(2) Thorax and particularly abdomen (terga lustrous) strikingly shining resulting from reduced microtomentum. Frontal triangle relatively shining despite sparse microtomentum. Sternopleuron completely blackish brown. Two or even three terminal segments of tarsi brown. Filum of distiphallus basally broad and distally without acute corner. Female unknown. .............. A. sp. nov. (1) near flavosterna

- Thorax and particularly abdomen with more grey microtomentum, abdominal terga never lustrous. Frontal triangle dull. Sternopleuron yellow at least on its ventral corner. Tarsi completely yellow. Filum of distiphallus basally slender and distally with acute corner in addition to slender curved projection (cf. RoHÁček 2006: fig. 361).

6(5) Pleural part of thorax with ventral half yellow and dorsal half pale brown; gonostylus with anterior (proximally) and posterior (more distally) margins convex, distinctly tapered towards the apex; posterior part of postgonite less projecting, with only 2 setae; spermathecae elongately pyriform.

A. sp. nov. (2) near flavosterna Pleural part of thorax largely brown to dark brown, only ventral corner of sternopleuron yellow; gonostylus with only anterior margin convex (ROHÁčEK 2006: fig. 362), less tapered towards apex; posterior part of postgonite more projecting, with 4 long setae (RoHÁČEK 2006: fig. 358); spermathecae ovoid (RoHÁČEK 2006: fig. 368).

\section{A. flavosterna Sueyoshi \& Roháček 2003}

\section{General discussion}

A total of eleven species of Anthomyzidae have now been reliably recorded from Taiwan. Although this number of species is the same as that reported from China (ROHÁČEK 2018), the true species richness in these two neighbouring countries must be very dissimilar. While the currently known anthomyzid taxa in China surely represent only a small fraction of the real fauna in this vast country (estimated to contain as many as $50-60$ species by ROHÁčEK 
2018), the diversity of this family in Taiwan can hardly reach half this number. Although a few additional genera (known from neighbouring areas), e.g. Arganthomyza Roháček, 2009 or Epischnomyia, have been expected to occur in Taiwan, only Amygdalops and Anthomyza species have been found so far.

The genus Amygdalops is represented by five species in Taiwan all of which seem to occur in lower-elevation tropical habitats, and may belong to the Oriental fauna. Three of these species, viz. Am. cuspidatus, Am. curtisi and Am. nigrinotum, are also known from some other parts of the Oriental Region, and the latter is even more widespread (cf. RoHÁČEK 2008). The remaining two new (but unnamed) species, Am. sp. nov. near cuspidatus and Am. sp. nov. near curtistylus, are yet known only from Taiwan but they likely also occur in adjacent Oriental areas, particularly in the Philippines, southern China or Indo-China. It can also be expected that a few other Amygdalops species, living in these areas, will eventually be found in Taiwan. The most probable candidates are $\mathrm{Am}$. bisinus Roháček, 2008 and Am. sevciki Roháček, 2018 (both known from nearby Hainan I. in SE China, see RoHÁČEK 2018) and Am. femorinus Roháček, 2009 (known only from Hahajima I. in southern Japan, ROHÁČEK 2009).

The situation with the genus Anthomyza is markedly different. All six species found in Taiwan proved to be undescribed species and all seem to be associated with high-montane or montane habitats. Moreover, their closest relatives are known from eastern Asia, mainly its Palaearctic part. These facts indicate that these Taiwanese Anthomyza species may be endemic to the island and probably evolved from ancestors that colonized Taiwan when it was connected with the Asian continent by land bridges (which happened several times during the Pleistocene Ice Ages, see LIN 1963). Anthomyza robusta sp. nov., occurring in the mountains of Chiayi and Nantou Counties, proved to be the sister species of $A$. trifurca which is widespread in eastern, mainly Palaearctic, Asia (Japan, Korean Penninsula, China: Sichuan, see RoHÁčEK 2006, 2009, 2018). This pair belongs to the A. bellatrix group containing further species also living in the latter area: A. bellatrix Roháček, 1984 in North Korea, Japan (Honshu) and Kuril Is. (RoHÁčEK 2006) and A. cuneata Roháček, 1987 in the mountains of Nepal and China (Sichuan) (RoHÁČEK 1987, 2018).

The most peculiar outcome of this study is the wholly unexpected diversity of the A. flavosterna group (established above) in Taiwan. There are (at least) five formerly unknown species in Taiwan while only one species, A. flavosterna, is known outside this island, occurring in the E. Palaearctic area and hitherto known only from Japan (Hokkaido, Honshu) and the Far East of Russia (Kuril Archipelago), see SUEYOSHI \& ROHÁčEK (2003), RohÁČEK $(2006,2009)$ and RoHÁČEK \& PrZHibORo (2016). It is even possible that the five species of the $A$. flavosterna group now known in Taiwan is not the final number. Consequently, this group of Anthomyza seems to have radiated extensively in the mountain ranges of Taiwan. Unfortunately, we do not have information about their habitat and host-plant associations to understand this distinctive diversification in more detail.

Based on available data, most species of Anthomyzidae were found in the Alishan Mts. Reserve (Chiayi County) besides $A$. robusta, two species of the A. flavosterna group were collected in this locality, viz. A. elongata and $A$. sp. nov (1) near flavosterna. It can be presumed that this area, and also the mountains in Nantou County, may host further endemic species of Anthomyza, and possibly some other Anthomyzidae (e.g. terricolous species of Stiphrosoma Czerny, 1928). However, because species of the latter genus can only be found close to the ground in tussocks of graminoids, they cannot be caught reliably by regular sweeping methods.

Judging from the above, still very incomplete, knowledge of Taiwanese Anthomyzidae and the known occurrence of members of this family in neighbouring countries, it is suggested that at least 20 species live in Taiwan. These can include not only additional species of Amygdalops and Anthomyza but, considering the insular character of the country, less probably some species of other genera, viz. Stiphrosoma, Arganthomyza or Epischnomyia.

Another phenomenon found in Taiwanese Anthomyzidae is noteworthy. The longitudinal ornamentation of the wings (Fig. 24) of $A$. caesarea sp. nov. (of the A. flavosterna group) represents the first reported occurrence in the genus Anthomyza. A highly similar pattern is known to occur in three other genera of Anthomyzidae, viz. Epischnomyia (in all three known E. Asian species), Ischnomyia Loew, 1863 (only in the Nearctic I. albicosta (Walker, 1849)) and Arganthomyza (only in the Nearctic Ar. vittipennis (Walker, 1857)). RoHÁČEK \& BARBER (2016: 44) discussed the causality of the parallel evolution of this wing pattern in North American species. Because the genus Anthomyza represents the fourth lineage where this wing pattern has occurred, it is likely that the main driver for its evolution is more general, most probably connected with the protection of these flies against attacks by predators through disruptive colouration (ROHÁČEK \& BARBER 2016, 1. c.).

\section{Conclusions}

(1) Considering the fact that Taiwan is an island, the species diversity of its fauna of Anthomyzidae may reach up to 20 species. It is expected that more than half of them, particularly the species restricted to montane habitats, will prove to be unnamed and endemic to the island. Because the current knowledge of Anthomyzidae in Taiwan is very limited due to lack of material, it is expected that further field work and study of newly obtained material will provide a very different perspective of the fauna of the area.

(2) The dark, longitudinal wing pattern has been found in the genus Anthomyza (normally having unicolourous wings) for the first time. This is the fourth lineage of Anthomyzidae where this type of ornamentation of the wing has been recorded. 


\section{Acknowledgements}

It is a pleasure to express my gratitude to all the curators who provided specimens of Anthomyzidae from Taiwan for examination, namely Z. Soltész (HNHM), T. Saigusa (SIINH), M. Tkoč (NMPC), J.-F. Tsai (NMNS) and M. von Tschirnhaus (Bielefeld, Germany). I am particularly obliged to T. Hayashi (Tokyo, Japan) who kindly gave me a series of specimens (collected by the Japanese dipterist K. Kanmiya in the Alishan Mts) more than 20 years ago. My special thanks are given to M. Tkoč (NMPC) who kindly provided photographs and information on the habitat and host plant of $A$. robusta from his field work in Taiwan, and to D. Zelený, vegetation ecologist of the National Taiwan University in Taipei, for identification of this plant. K. N. Barber (Sault Ste. Marie, Ontario, Canada) and A. G. Irwin (Norwich, U.K.) are cordially thanked for very helpful reviews of the manuscript and F.-S. Hu (Taichung, Taiwan) for corrections of locality names in Taiwan. This study was financially supported by the Ministry of Culture of the Czech Republic through the institutional financing of long-term conceptual development of a research institution (the Silesian Museum, MK000100595).

\section{References}

CUMMING J. M. \& WOOD N. D. 2010: 2. Adult morphology and terminology. Pp. 9-50. In: BROWN B. V., BORKENT A., CUMMING J. M., WOOD D. M., WOODLEY N. E. \& ZUMBADO M. A. (eds): Manual of Central American Diptera. Vol. 1. NRC Research Press, Ottawa, ix +714 pp

CUMMING J. M. \& WOOD D. M. 2017: 3. Adult morphology and terminology. Pp. 89-133. In: KIRK-SPRIGGS A. H. \& SINCLAIR B J. (eds): Manual of Afrotropical Diptera. Vol. 1. Introductory chapters and keys to Diptera families. Suricata Vol. 4. SANBI Graphics \& Editing, Pretoria, xiii +425 pp.

DELFINADO M. O. 1971: New species of shore flies from Hong Kong and Taiwan (Diptera: Canaceidae). Oriental Insects 5(1): 117-123.

GRIFFITHS G. C. D. 1972: The phylogenetic classification of Diptera Cyclorrhapha with special reference to the structure of the male postabdomen. Dr. W. Junk N. V., The Hague, 340 pp.

LIN C. C. 1963: 2. Geology and ecology of Taiwan prehistory. Asian Perspectives 7: 203-213.

LIN F.-J. \& CHEN Ch.-S. 1999: The name list of Taiwan Diptera. The Taiwan Fauna, No. 1. Academia Sinica, Taipei, Taiwan, R.O.C., ix +124 pp.

LIN F.-J., TSENG H.-C. \& LEE W.-Y. 1977: A catalogue of the family Drosophilidae in Taiwan (Diptera). Quarterly Journal of the Taiwan Museum 30(3): 345-372.

MCALPINE J. F. 1989: 116. Phylogeny and classification of the Muscomorpha. Pp. 1397-1518. In: McALPINE J. F. \& WOOD D. M. (eds): Manual of Nearctic Diptera. Agriculture Canada Monograph No. 32, Vol. 3, Minister of Supply and Services Canada, Ottawa, vi $+1333-1581 \mathrm{pp}$.

PAPP L. 2005: Some acalyptrate flies (Diptera) from Taiwan. Acta Zoologica Academiae Scientiarum Hungaricae 51(3): 187-213

ROHÁČEK J. 1987: Two new species of the Anthomyza gracilis-group (Diptera, Anthomyzidae) from Nepal. Acta Entomologica Bohemoslovaca 84: 48-59.

ROHÁČEK J. 1998: Taxonomic limits, phylogeny and higher classification of Anthomyzidae (Diptera), with special regard to fossil record. European Journal of Entomology 95: 141-177.

ROHÁČEK J. 2006: A monograph of Palaearctic Anthomyzidae (Diptera) Part 1. Časopis Slezského Zemského Muzea, Opava (A) 55(supplement 1): $1-328$.

ROHÁČEK J. 2008: Revision of the genus Amygdalops Lamb, 1914 (Diptera, Anthomyzidae) of the Oriental, Australasian and Oceanian Regions. Acta Zoologica Academiae Scientiarum Hungaricae 54: 325-400.

ROHÁČEK J. 2009: A monograph of Palaearctic Anthomyzidae (Diptera) Part 2. Časopis Slezského Zemského Muzea, Opava (A) 58(supplement 1): $1-180$.

ROHÁČEK J. 2013: New amber fossil Anthomyzidae (Diptera): an unexpected Eocene diversity. Journal of Systematic Palaeontology 11: 431-473.

ROHÁČEK J. 2018: First Anthomyzidae (Diptera) from China: a new genus, six new species and new records. Acta Entomologica Musei Nationalis Pragae 58: 35-76.

ROHÁČEK J. \& BARBER K. N. 2011: Quametopia, a new genus of Nearctic Anthomyzidae (Diptera), with description of two new species, immature stages and life history. European Journal of Entomology 108: $287-326$

ROHÁČEK J. \& BARBER K. N. 2016: Nearctic Anthomyzidae: a monograph of Anthomyza and allied genera (Diptera). Acta Entomologica Musei Nationalis Pragae 56(supplement): 1-412.

ROHÁČEK J., PETRÁKOVÁ L. \& TÓTHOVÁ A. 2019: Molecular phylogeny and timing of evolution of Anthomyza and related genera (Diptera: Anthomyzidae). Zoologica Scripta 48: 745-760.

ROHÁČEK J. \& PRZHIBORO A. 2016: Anthomyzidae (Diptera) of Iturup Island (Russia: Kuril Islands). Acta Musei Silesiae Scientiae Naturales 65: 203-213.

ROHÁČEK J. \& TÓTHOVÁ A. 2014: Morphology versus DNA - what will bring clarity to the relationships of phylogenetically unclear genera of Anthomyzidae (Diptera)? Arthropod Systematics and Phylogeny 72: 165-176.

SHIAO S.-H. 2019: Species checklist of Zeugodacus (Diptera: Tephritidae: Dacini) in Taiwan. Formosan Entomologist 39: 36-45.

SHIAO S.-H. \& WU W.-J. 1996: Four new agromyzid species from Taiwan. Transactions of the American Entomological Society 122(4): 213-226.

SUEYOSHI M. \& ROHÁČEK J. 2003: Anthomyzidae (Diptera: Acalyptrata) from Japan and adjacent areas. Entomological Science 6: $17-36$.

ZATWARNICKI T. 1996: A new reconstruction of the origin of eremoneuran hypopygium and its implications for classification (Insecta: Diptera). Genus 7: 103-175. 